\title{
Why Join a Team?
}

\author{
David J. Cooper ${ }^{\mathrm{a}}$, Krista Saral ${ }^{\mathrm{b}}$, Marie Claire Villeval ${ }^{\mathrm{c}}$
}

This version: 12 May 2020

\begin{abstract}
We present experiments exploring why high ability workers join teams with less able co-workers when there are no short-term financial benefits. We distinguish between two explanations: pro-social preferences and expected long-term financial gains from teaching future teammates. Participants perform a real-effort task and decide whether to work independently or join a two-person team. Treatments vary the payment scheme (piece rate or revenue sharing), whether teammates can communicate, and the role of teaching. High ability workers are more willing to join teams in the absence of revenue sharing and less willing to join teams when they cannot communicate. When communication is possible, the choice of high ability workers to join teams is driven by expected future financial gains from teaching rather than some variety of pro-social preferences. This result has important implications for the role of adverse selection in determining the productivity of teams.
\end{abstract}

JEL Codes: C92, D23, M52, M53, J24

Keywords: Teams, teaching, revenue sharing, social preferences, self-selection, experiment

${ }^{a}$ Florida State University Department of Economics and University of East Anglia School of Economics, 113 Collegiate Loop, PO Box 3062180 Tallahassee, FL 32306-2180, USA. E-mail: djcooper@fsu.edu

${ }^{\mathrm{b}}$ University of North Carolina at Charlotte Department of Economics, 9201 University City Blvd. Charlotte, NC 28223, USA; Webster University Geneva George Herbert Walker School of Business and Technology, Geneva, Switzerland; GATE, Ecully, France. E-mail: ksaral@uncc.edu

${ }^{c}$ Univ Lyon, CNRS, GATE UMR 5824, 93, Chemin des Mouilles, Ecully, F-69130, France; IZA, Bonn. Email: villeval@gate.cnrs.fr

Acknowledgments: We are grateful to participants at seminars at Florida State University, the University of Arkansas, the University of Sydney, the University of New South Wales, the University of Geneva, the University of Lausanne, the ASFEE conference in Nice, the COPE conference in Aachen, the ESA North American meeting in Antigua, the EWEBE workshop in Lyon, and the VBEN meeting in Vienna for useful comments. Financial support from the LABEX CORTEX (ANR-11-LABX-0042) of Université de Lyon, within the Programme Investissements d'Avenir (ANR-11-IDEX-007) operated by the French National Research Agency (ANR), is gratefully acknowledged. This research was performed within the framework of the INDEPTH program of IDEXLYON from Universite de Lyon within the Programme Investissements d'Avenir (ANR-16-IDEX-0005). 
1. Introduction: Team production and team-based compensation are ubiquitous in organizations (Bandiera et al., 2013; Owan, 2014). ${ }^{1}$ The successful use of teams is considered a major component of 'high performance work organizations' (Ichniowski et al., 1997; Ichniowski and Shaw, 1999). Potential benefits include synergies in problem-solving, complementarities between team members' inputs, better task coordination, knowledge transfer, and employee empowerment. However, the preceding implicitly assumes that using teams and/or team-based compensation does not affect the quality of the workers employed by an organization. In reality, workers choose between jobs and can avoid teams through choice of employment. It is well-known that a significant share of incentive pay's impact on productivity is due to selection (e.g., Lazear, 2000; Dohmen and Falk, 2011). By the same token, we cannot understand how team production and team-based incentives affect productivity without understanding who joins teams.

There are obvious gains to joining a team if strong complementarities are present, as the increased productivity from being in a team can offset any losses due to moral hazard or revenue sharing with lower ability individuals. But suppose workers have heterogeneous ability and perform a task with minimal complementarities between workers' efforts. Why would a high ability worker want to join a revenue sharing team? Standard economic arguments suggest they should prefer working individually for a piece rate because they are financially harmed by an incentive system that pools their output with the production of less able peers (Meidinger et al., 2003). Moreover, moral hazard should reduce team productivity (Alchian and Demsetz, 1972; Holmström, 1982), leading to lower earnings for team members. If myopic financial concerns drive the choice to join a revenue sharing team, only low ability individuals should be willing to join and the resulting adverse selection should harm the productivity of teams.

Yet, contrary to the preceding arguments, the limited empirical evidence on this question indicates that high ability workers are surprisingly willing to join revenue sharing teams. Hamilton et al. (2003) provide

\footnotetext{
${ }^{1}$ In the U.S., a survey of Fortune 1000 companies reveals that $70 \%$ of large firms use some form of team incentives (Lawler et al., 2001; Lawler and Mohrman, 2003). The share of large firms with more than one fifth of their employees in self-managed teams increased from 37\% to 66\% between 1987 and 1996 (Lazear and Shaw, 2007). In Europe, the incidence of teamwork varies across countries, from less than $55 \%$ of the companies in the south of Europe to more than $75 \%$ in the UK (EWCS 2000/2001; European Foundation for the Improvement of Living and Working Conditions; Kyzlinková et al., 2007). Similar trends can be observed in academic research (Wuchty et al., 2007).
} 
a striking result. They study a garment company that switched its payment scheme from individual piece rates to team compensation. The most skilled workers were disproportionately more likely to join a team voluntarily even though team compensation often led them to lose money. Hamilton et al. suggest that "teams offer nonpecuniary benefits to workers" (p. 469), possibly due to socialization.

We present laboratory experiments designed to study why high ability individuals might join revenue sharing teams in the absence of immediate financial benefits. Laboratory experiments are a useful complement to field studies of the economics of organizations because of the high degree of control available in the lab and the ability to observe process data, specifically conversations between teammates including attempts to teach. We designed an environment where we systematically change single elements of the environment between treatments, isolating specific explanations for high ability participants joining revenue sharing teams. To accentuate adverse selection, we study an intentionally tough environment with minimal complementarities and full information about relative ability. High ability participants who join teams have no reason to expect their productivity to increase and know they are sharing revenue with a lower ability participant. Our conclusions are presumably not specific to our setting, as adverse selection is a general phenomenon that should be present in less extreme environments (i.e., settings with stronger complementarities and less certainty about being high ability).

We explore two explanations for why high ability workers might join revenue sharing teams in spite of short-term losses. The first is that high ability workers are motivated by pro-social preferences. They might join a revenue sharing team to increase their low ability peers' earnings at the cost of their own, consistent with models of other-regarding preferences (e.g., Fehr and Schmidt, 1999; Bolton and Ockenfels, 2000). High ability workers might also enjoy the opportunity to interact socially with other workers, derive pleasure from teaching their less able peers, or view teaching as an alternative means of increasing the earnings of these peers. The second explanation is that high ability workers are motivated by long-term financial benefits. If they believe they can improve the performance of their less able teammates by teaching them, they might take a short-term financial hit due to revenue sharing in exchange for improving the longterm productivity of the team, especially if they anticipate mandatory team membership in the future. To 
separate these possible explanations, we study participants working on nonograms, a type of logic puzzle. Nonograms provide a challenging real-effort task where teaching is possible. Participants always solve the problems individually, eliminating any complementarities in production (i.e., positive synergies from having a team solve the puzzle).

The experiment contains three stages. In Stage 1, participants attempt to solve a series of nonograms with piece rate compensation for correct solutions. Prior to Stage 2, they are matched into heterogeneous pairs by ability, as measured by Stage 1 performance, and decide whether to continue working for an individual piece rate or to join a team with their partner (i.e., their potential teammate). ${ }^{2}$ The Stage 1 performance of the partners is common knowledge, so the high ability partner (i.e., the partner who did better in Stage 1) knows that their potential teammate is relatively poor at solving nonograms. Treatments, described below, vary how teams are paid and how teammates interact in Stage 2. In Stage 3, participants are forced to join a revenue sharing team with no direct interaction. Forced team membership in Stage 3 implies the existence of long-term benefits from teaching in Stage 2.

In the Baseline treatment, teams are paid in Stage 2 via revenue sharing. Teammates work on the puzzles individually but are paid based on the number of puzzles solved by the two teammates. Between puzzles, teammates can chat, providing an opportunity for social interaction as well as teaching. High ability participants are given hints about solving nonograms that can be passed on to their less able teammate. Partners know that hints will be available prior to choosing whether to join a team, making it transparent that teaching is possible.

The other treatments vary how attractive teams are relative to the Baseline treatment. In the Piece Rate treatment, teammates are paid a piece rate based on their individual output, rather than team output, eliminating the short-run financial disincentive for high ability subjects to join a team. The No Interaction treatment eliminates the chat between puzzles. Teaching is not possible, but a desire to increase the payoffs of their low ability peers can still motivate high ability participants to join teams. The New Partner

\footnotetext{
${ }^{2}$ We use the term "partner(s)" to refer to pairs of participants who are potentially teammates and the term "teammate(s)" to refer to participants who actually join a team together.
} 
treatment differs from the baseline by not holding partners fixed between Stages 2 and 3. High ability participants who join teams can still benefit from the joy of teaching, enjoyable social interactions, and financially helping their low ability teammate, but long-term financial gains from teaching are eliminated. Finally, high ability participants do not receive hints in the No Hints treatment, limiting the possibility of teaching and its associated benefits, pecuniary or otherwise.

A reason why a high ability participant might join a revenue sharing team involves pro-social preferences. The literature on group identity (e.g., Chen and Li, 2009) suggests that these preferences are stronger when social distance is low. A potential concern with our lab setting is that social distance may be higher than in field settings. Therefore, in all five treatments we vary whether subjects participate in an ice breaker task before beginning the experiment. This manipulates social distance, checking whether our conclusions are sensitive to the social distance between potential teammates.

Turning to the results, $32 \%$ of high ability participants are willing to join teams in the Baseline treatment. This doubles to $71 \%$ in the Piece Rate treatment and falls to $10 \%$ in the No Interaction treatment. High ability participants apparently regard revenue sharing as a negative aspect of joining a team and put little weight on improving the earnings of their low ability peer when no interaction is possible. At $13 \%$ and $15 \%$ respectively, their willingness to join teams is also quite low in the New Partner and No Hints treatments. Neither a desire for social interaction nor joy of teaching seems to motivate high ability participants to join teams. The Ice Breaker condition generates 31\% more conversation between partners when chat is possible, consistent with lowered social distance. However, this increase is confined to social interactions rather than teaching, and the Ice Breaker condition does not increase the willingness of high ability participants to join teams. Overall, the data indicate that high ability participants are almost never willing to join revenue sharing teams unless there is a possible future financial benefit from teaching.

Consistent with the importance of teaching, "wanted to teach partner" is by far the most common reason given by high ability participants for joining a team. Subsequent to joining teams, high ability participants with access to the hints often try to teach their teammate by using these hints. Surprisingly, teaching does not improve the performance of low ability teammates but instead improves the high ability teammates' 
own performance, consistent with results in educational and cognitive psychology about protégé effects. There is apparently some truth to the cliché that the best way to learn a topic is to teach it. This suggests that encouraging more able employees to teach co-workers may be a source of increased productivity, a benefit that should not be exclusively evaluated by the direct impact of teaching on those who are taught. The overall impact of team membership on earnings is low, but there is a positive relationship between the benefits of joining a team and the likelihood that high ability people join a team.

To summarize, we find little evidence that pro-social preferences motivate high ability participants to join teams. Rather, these participants are willing to join teams when they view the long-term financial gains from training their partners as outweighing any short-term losses due to revenue sharing.

The most important takeaway from our study is the simplest: strong adverse selection occurs in all of the treatments with revenue sharing teams. Since this finding is based on an artificial work environment, we must be cautious about its external validity. Nevertheless, we believe that any manager considering the adoption of such teams should understand the potentially negative effect of adverse selection on the quality of their workforce. We show that adverse selection into teams decreases in our experiment when high ability workers can reap the gains of mutual learning. To mitigate the effects of adverse selection, this suggests that the implementation of revenue sharing teams in companies should emphasize opportunities for mutual learning. Work environments should facilitate teaching within teams and stress stable team membership; these features can encourage high ability workers to join teams by increasing the odds that they reap the benefits of teaching. ${ }^{3}$

The remainder of this paper is organized as follows. Section 2 reviews the related literature. Section 3 introduces our experimental design and Section 4 presents our theoretical predictions. Section 5 develops our results. Section 6 discusses these results and concludes.

\footnotetext{
${ }^{3}$ There are several reasons for companies to make joining a team voluntary. High ability workers can always quit the company and go elsewhere when teamwork is introduced (Hamilton et al., 2003). Also, letting employees choose whether to work in a team may reinforce social identity and cohesion, enhancing the benefits of teams. Experiments have shown the benefits of self-selection and decentralized team formation for the profits of firms employing cooperative workers (Kosfeld and von Siemens, 2009), for coordination in weak-link games (Chen, 2017), on productivity in study teams (Chen and Gong, 2018), and for online crowdsourcing teams (Blasco et al., 2013).
} 
2. Related Literature: Empirical tests of team formation and team incentives remain scarce (Lazear and Shaw, 2007; List and Rasul, 2011; Charness and Kuhn, 2011). While the empirical literature has investigated extensively cooperation and free-riding in groups (see surveys by Chaudhuri, 2011, and Villeval, 2020) and more recently the dynamics of group composition (e.g., Bandiera et al., 2013; Chen and Gong, 2018, in the context of teamwork; Ahn et al., 2008; Charness and Yang, 2014, in the context of public good games), very few papers have explored selection into team-based compensation. The influential paper of Hamilton et al. (2003) studies a garment company switching from individual piece rates to a form of revenue sharing teams. They find that higher skilled employees are earlier volunteers to join teams even though this often harms their earnings. Babcock et al. (2015) present field experiments studying the effect of team incentives on class attendance and participation in exercise. In a follow-up treatment where subjects choose between individual and team-based compensation, $97 \%$ of students choose individual pay, avoiding guilt from letting down their teammate. The weak-link structure of payoffs, rather than revenue sharing, makes students worse off from choosing team-based compensation even if subjects have other-regarding preferences. ${ }^{4}$ Given the high level of risk and low incentives associated with joining a team, it is unsurprising that few choose this option. ${ }^{5}$

Several papers explore sorting into team-based compensation due to personal characteristics. Lab experiments by Kuhn and Villeval (2015) find that women are more willing than men to select team-based compensation over an individual piece rate in a setting without positive synergies from team production. They attribute this difference to women's greater optimism about the ability level of their co-workers, emphasizing the role of beliefs (see also Dohmen and Falk, 2011, and Wozniak et al., 2014). Women are especially likely to join teams when team formation requires mutual agreement, which is consistent with women having greater aversion to advantageous inequity. In an online experiment involving employees

\footnotetext{
${ }^{4}$ Specifically, we refer to distributional models like Fehr and Schmidt (1999) or Bolton and Ockenfels (2000). Holding attendance fixed, both teammates earn weakly less under team-based compensation.

${ }^{5}$ Kocher et al. (2006) study the choice to play a beauty contest game either individually or as part of a team. Subjects strongly prefer to join teams. All team members receive the full winning prize, so there are no earnings losses due to revenue sharing.
} 
and entrepreneurs, Cooper and Saral (2013) show that entrepreneurs have a lower preference for joining revenue sharing teams than otherwise similar business people. Czibor et al. (2017) report different results, with entrepreneurs not having systematically different preferences for joining teams. Positive synergies generated by joining a team lead to $90 \%$ of participants joining a team, so the lack of an effect may be due to hitting a ceiling. They show the importance of risk aversion and beliefs about potential partners (see also Bäker and Mertins, 2013) for not joining a team, but find no aversion to loss of power.

Our study has several features that distinguish it from existing studies. (1) We employ the strengths of lab experiments in ways that would be difficult for a field study to replicate. For example, we eliminate positive synergies to reduce the financial incentives for high ability participants to join teams, stressing the roles of long-term gains from teaching and pro-social preferences. We take advantage of the dialogues between teammates to directly observe when teaching occurs and how it affects performance. (2) Our experiment emphasizes the role of teaching and interaction between teammates. Peer-to-peer teaching is extremely limited in existing experimental studies, while our task is teachable. Elements like the hints and knowing their potential partner's ability make it transparent that teaching is possible and potentially beneficial. Allowing teammates to chat lets us study whether social interaction per se is an important benefit of joining a team. (3) We study the dynamic effects of team formation mechanisms by examining how the duration of a partnership influences the decision to join a team by affecting the returns to teaching. This highlights an issue that the existing literature has largely ignored.

Our primary interest is studying what motivates high ability participants to join revenue sharing teams, but we also contribute to the literature on joint problem-solving. A growing experimental literature shows that freely interacting teams making joint decisions are typically better at solving problems than individuals, but little work has been done on how the internal structure of teams affects their performance. ${ }^{6}$ Our study is unusual because we focus on teaching within teams followed by independent decision making rather than joint decision-making. ${ }^{7}$

\footnotetext{
${ }^{6}$ See Charness and Sutter (2012) for a summary of this literature.

${ }^{7}$ See Kimbrough et al. (2017) for related experiments on peer-to-peer teaching.
} 
In theory an optimal team compensation scheme can be designed to motivate agents to help others in joint production (Itoh, 1991), but empirical studies show that profit sharing has little effect on helping (e.g., Drago and Garvey, 1998). However, team members may be more willing to help if this is not detrimental to their own productivity (Oosterhof et al., 2009), as in our study where interactions take place during the feedback stage. While the interaction between skill diversity and peer learning has been recognized (Lazear, 1999), few studies have investigated this dimension (Owan, 2014). Hamilton et al. (2003) and Hoogendoorn et al. (2014) show evidence that skill heterogeneity increases productivity. Our study complements this literature by investigating whether the possibility of teaching influences more skilled individuals to team up with their less skilled peers.

\section{Experimental Design and Procedures:}

3.a. Task and Experimental Stages: Participants work at solving grid-based logic puzzles called nonograms. This is a challenging real-effort task with rules simple enough to be learned quickly. There are a number of tricks that make it easier to solve a nonogram, making it possible to teach within the context of a laboratory experiment. We use nonograms, rather than better-known puzzles such as Sudoku, to make it unlikely that participants would enter the session with previous experience. ${ }^{8}$ The main characteristics of this task capture features of many work tasks (e.g., software engineering; managing logistics such as fleet management, warehousing, or order fulfillment for an organization): subjects have to perform an actual task in a limited amount of time, this task requires skill, small errors can lead to failure because solving a puzzle is a cumulative process that relies on completing a sequence of small steps, and there exist rules that make success more likely.

Each session has three main stages where participants attempt to solve $7 \times 7$ nonograms. Each stage contains five periods. All subjects face the same puzzle during a period, making it possible for them to discuss how to solve the puzzle when working in teams. Figure 1 presents a sample nonogram (puzzle + solution), showing both the blank (left) and solved (right) versions of the puzzle. Solving the puzzle requires

\footnotetext{
${ }^{8}$ Supporting our conjecture that solving nonograms can be taught in a lab setting, several studies have shown that Sudoku puzzles are teachable (Calsamiglia et al., 2013; Kimbrough et al., 2017).
} 
determining which squares in the grid should be filled. The numbers given to the left of the rows and above the columns show the runs of filled squares in each row or column. For example, the numbers 1 and 4 appear to the left of the first row of the example. This means that the row contains a single filled square followed by a run of four consecutive filled squares. In many cases, there are only a limited number of ways to fill in a row or column. For instance, there is only one way to fill in the fifth and seventh columns of the example. Knowing these simple rules makes it far easier to solve a nonogram.
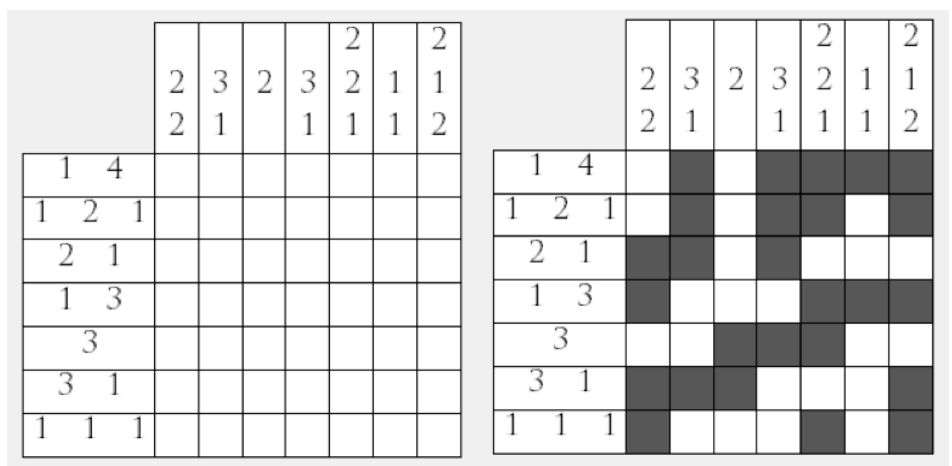

\section{Figure 1: Example of a nonogram and its solution}

Participants have 90 seconds to solve each puzzle. They can check their answer at any time by pressing an on-screen button. After each puzzle, they view a feedback screen for 60 seconds. The feedback gives their number of errors, if any, and their earnings for the round. Participants can also toggle between viewing the solution to the puzzle, their final answer to the puzzle with any incorrect cells marked by a red X, and an animated replay of how they solved the puzzle with mistakes marked as they occurred. The replay can be paused at any point, giving subjects a better opportunity to think about points where they made a mistake.

During Stage 1 (Rounds $1-5$ ) of the experiment, participants are paid an individual piece rate of 1.25 Euro per correctly solved puzzle. At the end of Stage 1, each participant receives feedback on the average, median, maximum, and minimum numbers of puzzles solved in Stage 1 by all participants in the same session. Based on Stage 1 performance, participants are divided into "high ability" and "low ability" types. A participant is designated as a high ability (low ability) type if their performance is above (below) the median Stage 1 performance for that session. Any ties are broken randomly so that an equal number of 
subjects are assigned to each type. The labels "high ability" and "low ability" are not used in the experimental materials (see instructions in Online Appendix 1).

Immediately following Stage 1, participants in most sessions are informed that the top half of the participants in terms of puzzles solved in Stage 1 (i.e., high ability types) will receive a "tool." This tool is a list of hints for solving the puzzles. These hints include all the possible fixed pattern rules for the $7 \mathrm{x} 7$ puzzles. High ability types view abbreviated hints on their screens for the remaining two stages and receive an expanded version in paper form (see Figure A1 in Online Appendix 2). Participants are also informed that participants in the bottom half of Stage 1 performance (i.e., low ability types) will receive a form with empty grids (see Figure A1 in Online Appendix 2). This facilitates the transfer of hints from one partner to the other when participating in teams and avoids identifying the type of subjects by whether they receive a form. ${ }^{9}$ Giving hints provides the high ability types with a natural way to teach low ability types by sharing the hints. Indeed, we realized in conducting pilot sessions that teaching was difficult without giving subjects some hints. Not giving hints to low ability types captures the fact that, in field settings, less educated workers receive significantly less firm-sponsored training than high educated workers, either because it is less costly to teach high ability employees or because the returns are higher from training high ability employees (e.g., Dostie, 2015).

The task in Stage 2 is identical to Stage 1. Participants work individually to solve a series of five nonograms, with 90 seconds for each puzzle. The difference is that participants are randomly matched in pairs consisting of one high ability type and one low ability type. Prior to solving nonograms in Stage 2, partners (i.e., potential teammates) choose between two options on how to interact.

Option 1 is always to work as an individual, largely as in Stage 1. Under Option 1, participants solve the puzzles individually, receive an individual piece rate of 1.25 Euro per correctly solved puzzle, and do

\footnotetext{
${ }^{9}$ Providing the hints only to the high ability participants could have generated an emotional reaction in the low ability participants, especially if they felt it was unfair that high ability participants received hints while they did not. However, comparing low ability participants assigned to Option 1, the number of puzzles solved in Stages 2 and 3 does not differ between the NH treatment and the other treatments. This suggests that the performance of low ability types was not affected by discouragement due to a lack of hints or a reluctance to help high ability participants because it was unfair that only high participants had the hints.
} 
not interact directly with their partner (i.e., there is no chat). The only difference from Stage 1 is that Option 1 allows participants to receive feedback for themselves and their partner. Specifically, the feedback screen following each puzzle gives participants access to the solution of the puzzle, outcomes, and replays for themselves and their partner. The feedback phase lasts for 90 seconds rather than the 60 seconds used in Stage $1 .^{10}$

Option 2 varies between treatments but always involves some version of joining a team. Changing Option 2 is the primary manipulation in our experimental design. Section 3.b describes the different versions of Option 2 in detail.

Partners simultaneously choose either Option 1 or Option 2. Prior to this choice, participants receive feedback showing their Stage 1 performance and classification of their performance as above or below the median performance (i.e., high or low ability), as well as the Stage 1 performance and classification of their partner. The instructions remind them that participants with the hints (when available) are matched with participants without the hints. The partners are not able to communicate prior to choosing an option. If both subjects choose the same option, they play the agreed upon option. If there is disagreement, a random draw determines which option is assigned to the pair.

Comparing behavior and outcomes across options and across treatments is problematic because assignment to an option is endogenous. Thus, estimated treatment effects may be biased due to selection. To make it possible to use a Heckman correction, a small fixed payment is associated with each option. These are drawn independently from a uniform distribution between 0 and 100 Euro cents and are paid only once. We use the difference between these two Heckman draws as an instrument when correcting for selection.

After Stage 2, subjects receive feedback on their own and their partner's Stage 2 performance and the average, median, maximum, and minimum Stage 2 performance across all participants in the session. Except in the New Partner treatment, described below in Section 3.b, participants are paired with the same

\footnotetext{
${ }^{10}$ More time was necessary to allow for chat in treatments with interaction. The time was expanded for both options in all treatments to maintain parallelism.
} 
partner for Stage 3 as in Stage 2. This is true regardless of which option the pair chooses or is assigned in Stage 2. In each pair, the two partners solve five nonograms individually and equally split the piece rate of 1.25 Euro per correctly solved puzzle. There is no interaction (chat) between partners in Stage 3. The feedback phase after each period only lasts for 60 seconds since there is no chat, but otherwise remains the same as in Stage 2. Stage 3 uses the same five puzzles as Stage 2, but the rows and columns are flipped. This makes differences between Stage 2 and 3 performances a direct measure of learning between these two stages, while disguising the fact that identical puzzles are used. ${ }^{11}$

When choosing an option prior to Stage 2, participants know what is coming in Stage 3 - revenue sharing teams with no chat - and whether they will be paired with the same or a different partner in Stages 2 and 3. This feature of our design, forcing all individuals to join teams for Stage 3, is guided by our identification strategy: indeed, it allows us to test whether teaching is motivated by social preferences or the expected monetary returns from teaching and learning. Unlike in our experiment, workers in real-world settings can quit when their company makes revenue sharing compulsory. However, teamwork is becoming more common over time (see fn 1), implying that external mobility will no longer serve as an easy way to avoid it. If high ability types know that they will eventually have to join a team someplace, they have a reason, as in our experiment, to join a team early and improve their co-workers.

After Stage 3, participants fill out a questionnaire that asks the reasons for their option choice, if they would pick the same option again, and whether they used the hints (when available). We also collect basic demographic information. Finally, to obtain a measure of reasoning ability, we give participants three minutes to answer the three questions from Frederick's (2005) Cognitive Reflection Test (CRT) and pay them 50 Euro cents for each correct answer.

3.b. Treatments: The experimental design has a $5 \times 2$ structure, summarized in Table 1 . The five primary treatments systematically vary Option 2 through the type of pay scheme, the ability to interact via chat

\footnotetext{
${ }^{11}$ Participants could not view puzzles from previous periods. We believe it is exceedingly unlikely that a participant would recognize a puzzle they had faced five periods earlier with the rows and columns flipped.
} 
between teammates, the matching for Stage 3, and the availability of hints. The five versions of Option 2 are as follows:

1) Baseline (BL): Participants solve the puzzles individually and the two teammates equally split the piece rate of 1.25 Euro per correctly solved puzzle in the pair. During the feedback phase, subjects can message with their teammate via a chat program, described below. Feedback is otherwise the same as in Option 1. Option 2 in the BL treatment includes all the features that might affect the willingness of high ability types to join teams in the field (relative to working individually for a piece rate): revenue sharing, the ability to teach, the possibility of social interaction, and a relatively long-term relationship. Each of the other four treatments changes a single element from the BL treatment, removing one of these features.

2) Piece Rate (PR): Participants solve the puzzles individually and receive an individual piece rate of 1.25 Euro per correctly solved puzzle. Relative to the BL treatment, the only change to Option 2 in the PR treatment is the elimination of revenue sharing.

3) No Interaction (NI): Participants solve the puzzles individually and the two teammates equally split the piece rate of 1.25 Euro per correctly solved puzzle in the pair. Teammates do not have the ability to interact via chat during the feedback phase. This is the only difference between the BL and NI treatments. 4) New Partner (NP): The only difference between the BL and NP treatments is the matching of participants in Stage 3. Recall that for all treatments other than NP, participants are matched with the same partner in Stages 2 and 3. In the NP treatment, participants receive a new partner in Stage 3, with each pair still containing one high ability type and one low ability type. At the beginning of Stage 3, participants in the NP treatment see information on their new partner's Stage 1 and 2 performances, classification (high or low ability), and possession of the hint. This matches what is known about Stage 3 partners in the other treatments. Note that it is still possible to teach in the NP treatment; what is eliminated relative to the BL treatment is much of the incentive to do so.

5) No Hints (NH): The only difference between the BL and NH treatments is the information given to high ability types. High ability types do not receive hints in the NH treatment. This is intended to minimize the possibility of teaching. 
In all versions of Option 2, with the exception of the NI treatment, teammates can chat during the feedback phase via typed text messages in a chat box. Subjects are told they can share any information they like with their teammates except for their identity. This specifically includes the information in the hints (except in $\mathbf{N H})$.

The second dimension of the $5 \times 2$ design varies social distance between subjects. Specifically, some sessions include an ice breaker activity prior to the distribution of instructions to reduce social distance (Ice Breaker). This is a form of interpersonal bingo, referred to as the "autograph game," which encourages the participants to interact in a way that is not related to the nonogram task. Subjects receive a sheet of paper printed with a $4 \times 4$ grid of 16 simple facts about people (e.g., "Owns a cat"). ${ }^{12}$ To fill a cell, they have to find another participant from that session who fits that fact and have them sign their sheet in the cell. The goal is to have four signed cells in a row, column, or diagonal. They can only have another participant sign their sheet once and cannot sign their own sheet. The sheet is described to participants as a way to get to know each other, and there is no reward for completing it. There is no time limit. The task took $10-15$ minutes to complete and generated a great deal of social interaction between participants.

In contrast to Chen and Lim (2013) and Lim and Chen (2014), we induce socialization at the session level rather than the group or pair level. There are a couple of reasons for this. First, reducing anonymity about who is less or more able at the task could cause emotional discomfort for the subject who learns he or she is less able. The Ice Breaker condition is intended to reduce social distance between partners. Beyond ethical concerns about causing emotional distress, we feared that reducing anonymity would increase social distance due to the resulting discomfort, limiting the difference between the conditions with and without the Ice Breaker. Second, our objective is to induce non-strategic socialization, totally independent of the content of the task. This would be difficult if the Ice Breaker was at the level of pairs since the assignment

\footnotetext{
${ }^{12}$ There are two versions of the sheet, which are randomly assigned to participants in Ice Breaker sessions. We use two sheets to increase interactions. See Figure A2 in Online Appendix 2 for copies.
} 
of subjects to pairs is based on their relative ability at the task; the Ice Breaker would need to take place after Stage 1.

3.c. Procedures: The experiment consists of 23 sessions with 474 subjects. All sessions were conducted at GATE-Lab (Groupe d'Analyse et de Théorie Economique) in Lyon, France between November 2015 and February 2016, except for two sessions of the NH treatment under the Ice Breaker condition that were conducted in October 2018. Subjects were undergraduate students from the local engineering and business schools, recruited using ORSEE software (Greiner, 2015). The experiment was programmed using z-Tree software (Fischbacher, 2007). Average earnings were 17.02 Euro and sessions lasted roughly 90 minutes. Table 1 summarizes the number of sessions and subjects for each cell of the $5 \times 2$ design, as well as the main features of each treatment. With a few exceptions, we ran two sessions in each cell of the design. ${ }^{13}$

Table 1: Summary of Treatments

\begin{tabular}{|c|c|c|c|c|c|c|c|}
\hline & & $\begin{array}{c}\text { No Ice } \\
\text { Breaker }\end{array}$ & $\begin{array}{c}\text { Ice } \\
\text { Breaker }\end{array}$ & $\begin{array}{l}\text { Revenue } \\
\text { Sharing } \\
\end{array}$ & Chat & $\begin{array}{l}\text { Same } \\
\text { Partner }\end{array}$ & Hints \\
\hline \multirow{2}{*}{ Baseline (BL) } & \# Sessions & 3 & 2 & \multirow{2}{*}{$X$} & \multirow{2}{*}{$\mathrm{X}$} & \multirow{2}{*}{$\mathrm{X}$} & \multirow{2}{*}{$\mathrm{X}$} \\
\hline & \# Subjects & 64 & 48 & & & & \\
\hline \multirow{2}{*}{$\begin{array}{l}\text { Piece Rate } \\
\text { (PR) }\end{array}$} & \# Sessions & 2 & 2 & \multirow{2}{*}{-} & \multirow{2}{*}{$\mathrm{X}$} & \multirow{2}{*}{$\mathrm{X}$} & \multirow{2}{*}{$\mathrm{X}$} \\
\hline & \# Subjects & 42 & 46 & & & & \\
\hline \multirow{2}{*}{$\begin{array}{l}\text { No Interaction } \\
\text { (NI) }\end{array}$} & \# Sessions & 3 & 2 & \multirow{2}{*}{$X$} & \multirow{2}{*}{-} & \multirow{2}{*}{$\mathrm{X}$} & \multirow{2}{*}{$\mathrm{X}$} \\
\hline & \# Subjects & 58 & 42 & & & & \\
\hline \multirow{2}{*}{$\begin{array}{l}\text { New Partner } \\
\text { (NP) }\end{array}$} & \# Sessions & 3 & 2 & \multirow{2}{*}{$X$} & \multirow{2}{*}{$\mathrm{X}$} & \multirow{2}{*}{ - } & \multirow{2}{*}{$\mathrm{X}$} \\
\hline & \# Subjects & 50 & 42 & & & & \\
\hline \multirow{2}{*}{$\begin{array}{l}\text { No Hints } \\
\text { (NH) }\end{array}$} & \# Sessions & 2 & 2 & \multirow{2}{*}{$X$} & \multirow{2}{*}{$\mathrm{X}$} & \multirow{2}{*}{$\mathrm{X}$} & \multirow[b]{2}{*}{-} \\
\hline & \# Subjects & 34 & 48 & & & & \\
\hline
\end{tabular}

\footnotetext{
${ }^{13}$ There was one BL session where the post-experimental questionnaire failed to run. For this session we are missing CRT scores and the questionnaire about the choice of option. In regressions that include a control for the CRT score, the value for data from this session is set equal to the average by type. This session is not included in the analysis of reasons for choosing Option 2. In one of the NI sessions, the program ran incorrectly for two of the puzzles in Stage 2. The analysis of performance in Stages 2 and 3 drops the data from this session. Replacement sessions were run for both of the sessions where we had problems with the program. We also have an extra session in the NP treatment. This was a pure mistake and does not reflect any problem with the first two sessions in this cell.
} 
4. Theory and Hypotheses: This section develops a simple theory of choosing between Options 1 and 2 and then presents hypotheses about treatment effects drawn from the theory. These hypotheses guide our data analysis.

4.a. A Simple Theory: Let $S_{i}^{t}(\tau)$ be the number of puzzles solved by a participant of type $i \in\{\mathrm{H}, \mathrm{L}\}$ in Stage $t$ as a function of whether teaching has occurred $(\tau=1)$ or not $(\tau=0)$. We make the following simplifying assumptions about production and teaching.

- The number of puzzles solved is a random variable; $E S_{i}^{t}(\tau)$ refers to the expected value of $S_{i}^{t}(\tau){ }^{14}$

- High ability types teach low ability types when they can chat and the high ability type has received the hints. Otherwise, teaching does not occur.

- Teaching improves productivity (i.e., the ability to solve puzzles) for low ability types $\left(E S_{L}^{t}(1)>E S_{L}^{t}(0)\right)$ and has no effect on high ability types $\left(E S_{H}^{t}(1)=E S_{H}^{t}(0)\right)$.

- Teaching takes place across the course of Stage 2 and has a persistent effect, implying that the effect of teaching is larger in Stage 3 than Stage 2: $E S_{L}^{3}(1)-E S_{L}^{3}(0) \geq E S_{L}^{2}(1)-E S_{L}^{2}(0)$.

The utility for a participant of type $i \in\{\mathrm{H}, \mathrm{L}\}$ in Stage $t$ is given by (1), which incorporates a simple form of other-regarding preferences. The first two terms of (1) are a weighted average of the participant's monetary payoff $\pi_{i}^{t}$ and their partner's monetary payoff $\pi_{j}^{t}$, where $\alpha$ is the weight that they put on their own payoff. Define $\theta_{i}^{t}(\tau)$ as the non-pecuniary benefits (if positive) or costs (if negative) of teaching for a participant of type $i \in\{\mathrm{H}, \mathrm{L}\}$ in Stage $t$. Normalize $\theta_{i}^{t}(0)=0$ for both types. This term does not represent the monetary benefits of teaching due to changes in productivity, but instead captures psychological factors such as "joy of teaching" for high ability types. The non-pecuniary benefits (or costs) of teaching accrue in Stage 2 when teaching actually occurs. Let $\mu_{i}^{t}$ represent the benefits of social interaction (i.e., interactions

\footnotetext{
${ }^{14}$ This assumes that effort plays no role, which is a simplifying assumption designed to match our experimental setup. We purposefully eliminated any outside options (i.e., access to internet, mobile phones, other paid tasks), so the opportunity cost of working on the puzzles was essentially zero.
} 
that do not involve teaching) for a participant of type $i \in\{\mathrm{H}, \mathrm{L}\}$ in Stage $t$. Social interaction occurs in Stage 2 if chat is available.

$$
U_{i}^{t}\left(\pi_{i}^{t}, \pi_{j}^{t}\right)=\alpha \pi_{i}^{t}+(1-\alpha) \pi_{j}^{t}+\theta_{i}^{t}(\tau)+\mu_{i}^{t}
$$

We make the following assumptions about the utility function of participants.

- Participants put more weight on their own payoff than their partner's payoff: $1 \geq \alpha \geq 1 / 2$.

- For high ability types, $\theta_{H}^{2}(1) \geq 0$; teaching is pleasurable and involves minimal effort.

- $\quad$ For low ability types, $\theta_{L}^{2}(1)=0$; being taught is neither costly nor pleasurable.

- Interacting with a partner is inherently enjoyable: $\mu_{i}^{t} \geq 0$.

Participants select the option that maximizes the sum of their expected utilities for Stages 2 and 3 plus an error term capturing the effect of the Heckman draws. A participant's choice should be independent of their beliefs about their partner's choice. If their partner's choice is the same as their preferred option, they are certain to get their preferred option by choosing it. If their partner's choice is not their preferred option, they have a $50 \%$ chance of getting their preferred option by choosing it rather than a $0 \%$ chance.

The predictions of the model depend on the nature of Option 2. We first consider the NI treatment where neither teaching nor social interactions take place.

(1) NI: Expected utility in Stage 3 is identical for both options given that the pay scheme is the same for both options and neither teaching nor social interactions are possible. Therefore, the choice between options reduces to a comparison of expected utilities in Stage 2. Option 2 is chosen if the following inequality holds, where $p$ is the piece rate and $\varepsilon$ is an error term capturing the Heckman draws. ${ }^{15}$

$$
(\alpha-0.5) p\left(E S_{j}^{2}(0)-E S_{i}^{2}(0)\right)+\varepsilon>0
$$

The term on the left gives the gains or losses from revenue sharing in Stage 2. This is positive for a low ability type and negative for a high ability type. Ignoring the error term, low ability types will always choose

15 The two expected utilities are compared by the following inequality: $\alpha \mathrm{pES}_{\mathrm{i}}^{2}(0)+(1-\alpha) \mathrm{pES}_{\mathrm{j}}^{2}(0)<$ $\alpha\left(0.5 p \mathrm{pS}_{\mathrm{i}}^{2}(0)+0.5 \mathrm{pES}_{\mathrm{j}}^{2}(0)\right)+(1-\alpha)\left(0.5 \mathrm{pES}_{\mathrm{i}}^{2}(0)+0.5 \mathrm{pES}_{\mathrm{j}}^{2}(0)\right)+\varepsilon$. This simplifies to (2). The preceding is slightly simplified, as $\varepsilon$ is actually the sum of two Heckman draws weighted by $\alpha$. 
Option 2 (revenue sharing teams) and high ability types will always choose Option 1 (piece rate). For subsequent treatments, we only consider predicted choices for high ability types. Ignoring the error term, low ability types are always predicted to choose Option 2.

$$
\begin{gathered}
0.5 p\left(E S_{L}^{2}(1)-E S_{L}^{2}(0)\right)+0.5 p\left(E S_{L}^{3}(1)-E S_{L}^{3}(0)\right)+\theta_{H}^{2}(1)+\mu_{H}^{2}+\varepsilon \\
>(\alpha-0.5) p\left(E S_{H}^{2}(0)-E S_{L}^{2}(0)\right)
\end{gathered}
$$

(2) BL: High ability types will choose Option 2 if the positive effect of teaching, both in terms of gains from increased productivity of the low ability type and non-pecuniary benefits, plus the benefit from social interaction is large enough to offset the expected loss of payoffs in Stage 2 due to revenue sharing. The inequality shown in (3) captures this tradeoff. The first two terms on the left side are monetary gains from teaching the low ability type. The third and fourth terms are non-pecuniary benefits of teaching and utility from social interaction. The right side, transcribed from (2), is the expected loss from Stage 2 revenue sharing. Option 2 is chosen if (3) holds (i.e., the gains from teaching and social interaction outweigh the losses due to revenue sharing).

(3) PR: There is no revenue sharing in the PR treatment. Thus, the right side of (3) equals zero. Since the left side of (3) is strictly positive, ignoring the error term, high ability types always choose Option 2.

(4) NP: The high ability types do not reap any monetary benefits from Stage 2 teaching in Stage 3 of the NP treatment. The second term of (3) is therefore dropped, yielding (4). The benefits of teaching are lower in the NP treatment than in the BL treatment and high ability types are less likely to choose Option 2.

$$
0.5 p\left(E S_{L}^{2}(1)-E S_{L}^{2}(0)\right)+\theta_{H}^{2}(1)+\mu_{H}^{2}+\varepsilon>(\alpha-0.5) p\left(E S_{H}^{2}(0)-E S_{L}^{2}(0)\right)
$$

(5) NH: Without hints, teaching is no longer possible and (4) becomes (5). Given that any benefits of teaching are eliminated, high ability types are less likely to choose Option 2 in the NH treatment than in the NP treatment. They may still choose Option 2 if the benefits of social interaction are sufficiently high.

$$
\mu_{H}^{2}+\varepsilon>(\alpha-0.5) p\left(E S_{H}^{2}(0)-E S_{L}^{2}(0)\right)
$$


4.b. Hypotheses: The hypotheses below follow directly from the theory but are also quite intuitive in nature. Inequality (3) leads directly to H1. Intuitively, revenue sharing increases the earnings of low ability types and decreases the earnings of high ability types. In the absence of teaching or social interactions, this makes Option 2 more attractive for low ability types. Indeed, the only reason we ever expect low ability types to choose Option 1 and high ability types to choose Option 2 in the NI treatment is random noise.

H1: Low ability types will choose Option 2 more often than high ability types in the NI treatment.

The remaining hypotheses compare the behavior of high ability types across treatments. The main takeaway from (3) is that Option 2 becomes more attractive with interaction because of the benefits of teaching and social interaction. These benefits are maximized in the BL treatment.

H2: High ability types will choose Option 2 more often in the $\boldsymbol{B L}$ treatment than in the NI treatment.

Comparing Option 2 in the PR and BL treatments, the only difference is that high ability types do not bear costs from revenue sharing in Stage 2 of the PR treatment. This leads to H3. The only reason for a high ability type to choose Option 1 in the PR treatment is random noise.

H3: High ability types will choose Option 2 more often in the PR treatment than in the $\boldsymbol{B L}$ treatment.

Reducing the benefits of teaching by rematching partners in the NP treatment or largely eliminating the benefits by removing hints, as captured in (4) and (5) respectively, should make Option 2 less attractive for high ability types.

H4: High ability types will choose Option 2 less often in the NP treatment than in the BL treatment.

H5: High ability types will choose Option 2 less often in the NH treatment than in the NP treatment.

The Ice Breaker condition should have an effect through two channels. First, the model includes benefits from social interaction $\left(\mu_{i}^{t}\right)$. Presumably, participants enjoy interaction more when social distance between them is lower, which is the intended effect of the Ice Breaker condition. Therefore, the Ice Breaker condition should lead to more high ability types choosing Option 2 in the treatments with Stage 2 chat (BL, PR, NP, and NH). Along similar lines, we have thus far assumed that $\alpha$ is fixed, but lower social distance produced by the Ice Breaker condition may lower $\alpha$ (putting relatively more weight on the partner's payoff). This implies a more frequent choice of Option 2 by high ability types in the revenue 
sharing treatments (BL, NI, NP, and NH). High ability types should be more willing to sacrifice earnings to help low ability types when they feel closer to them.

Combining the preceding observations yields $\mathbf{H 6}$.

H6: High ability types will choose Option 2 more often with the Ice Breaker condition in all five primary treatments (BL, PR, NI, NP, and $\mathbf{N H})$.

Our formal model and hypotheses focus on the question that this experiment is designed to address: when do individuals, particularly high ability individuals, join teams? The model assumes that teaching achieves its intended goal of improving performance by low ability types and that high ability types correctly anticipate its positive effects. We state no formal hypotheses about these issues, but will examine them carefully in the results section.

The model mimics our experimental environment by including no direct complementarities in team production. In Appendix 3, we extend the model to allow for complementarities. Adding complementarities does not affect our hypotheses about likely treatment effects.

5. Results: We first analyze the willingness of high ability types to join a team. Then, we examine whether high ability types try to teach their teammate and whether this improves their performance. Last, we study the earnings from joining a team.

5.a. Treatment Effects on Choice of Option 2: To discuss whether differences between treatments are statistically significant, we first consider non-parametric tests. Unless otherwise noted, the reported test statistic is a Pearson's $\chi^{2}$ test. We treat each subject as an independent observation since participants do not work in teams prior to choosing an option. We later supplement the results of the $\chi^{2}$ tests with regression analysis using probit models, but this has little effect on our conclusions.

Table 2 summarizes how frequently subjects choose Option $2 .{ }^{16}$ The data are broken down by ability (low or high) and primary treatment (BL, PR, NI, NP, and NH). H1 predicts that low ability types will be more likely to choose Option 2 than high ability types in the NI treatment. The data support this prediction

\footnotetext{
${ }^{16}$ Note that this is not the same as being assigned Option 2. If two partners choose different options, it is randomly determined whether they are assigned Option 1 or Option 2.
} 
and the difference is significant $(p<0.001) .{ }^{17}$ However, the NI treatment illustrates a seemingly odd feature of our data.

Table 2: Choice to Join a Team (Option 2)

\begin{tabular}{cccc}
\hline Treatment & \# Obs. per Type & Low Ability & High Ability \\
\hline BL & 56 & $57.1 \%\left(\right.$ base for $\left.\chi^{2}\right)$ & $32.1 \%\left(\right.$ base for $\left.\chi^{2}\right)$ \\
\hline PR & 44 & $65.9 \%$ & $70.5 \% * * *$ \\
\hline NI & 50 & $62.0 \%$ & $10.0 \% * * *$ \\
\hline NP & 46 & $60.9 \%$ & $13.0 \% * *$ \\
\hline NH & 41 & $65.9 \%$ & $14.6 \% * *$ \\
\hline
\end{tabular}

Notes: Stars indicate the level of significance of Pearson's $\chi^{2}$ tests comparing each treatment, by ability type, with the BL treatment. There are no stars in the row for the BL treatment, since this serves as the reference for the test. Three $(* * *)$, two $(* *)$, and one $(*)$ stars indicate significance at the $1 \%, 5 \%$, and $10 \%$ level, respectively.

Across the four treatments where Option 2 involves revenue sharing, 38\% of low ability types opt for the piece rate over revenue sharing and there are no significant differences across treatments. Even for low ability types who solve zero problems in Stage 1, and hence would benefit the most from revenue sharing, $26 \%$ still choose the piece rate. The apparent oddity of many low ability types eschewing revenue sharing reflects the powerful impact of the Heckman draws on option choice. For low ability types who pick the piece rate, the Heckman draw averages 0.31 Euro more for Option 1 than for Option 2, and 84\% have a larger Heckman draw for Option 1. Despite this feature, the fraction of low ability types choosing Option 2 remains higher than the fraction of high ability types making such a choice. This leads to our first result.

Result 1: When interaction through chat is not available in Stage 2 (NI), fewer high ability types choose revenue sharing than low ability types. This is consistent with $\boldsymbol{H} \mathbf{1}$.

A primary reason we are interested in who joins teams is that voluntary team membership could lead to adverse selection. Indeed, there is strong adverse selection in the NI treatment. Average Stage 1 performance for participants who choose Option 2 is 1.83 puzzles solved $v s .2 .95$ puzzles solved for all participants in the NI treatment. Strong adverse selection is also observed in the other three treatments (BL,

\footnotetext{
${ }^{17}$ For this test, an observation is a pair. We use a Wilcoxon signed-rank test to test whether the difference between the choices of the high and low ability types equals zero.
} 
NP, and NH) with revenue sharing teams, as can be seen from the relatively low percentage of high ability types who choose Option 2. Only in the PR treatment is adverse selection not present.

We now get to the central question of our paper: why would high ability participants join a team? In the NI treatment, revenue sharing harms high ability types and they have no opportunity to teach or socially interact. The only reason for a high ability type to join a team is a desire to improve the payoff of their low ability partner. This apparently matters little since few high ability types choose Option 2 . In contrast, the BL treatment allows teaching, with the associated financial and non-pecuniary benefits, as well as social interaction. Reflecting these improved incentives, the rate of choosing Option 2 by high ability types rises significantly from $10 \%$ in the NI treatment to $32 \%$ in the BL treatment $(p=0.006)$. This leads to our second result.

Result 2: Consistent with $\mathbf{H 2}$, high ability types choose Option 2 more often in the $\boldsymbol{B L}$ treatment than in the NI treatment.

The only difference between the $\mathbf{P R}$ and $\mathbf{B L}$ treatments is that high ability types do not bear a revenue sharing cost from choosing Option 2. This should maximize the attractiveness of Option 2, and indeed the rate of choosing Option 2 by high ability types more than doubles relative to the $\mathbf{B L}$ treatment (71\% vs. $32 \% ; p<0.001) .{ }^{18}$ This leads to our third result.

Result 3: Consistent with $\mathbf{H 3}$, high ability types choose Option 2 more often in the PR treatment than in the $\boldsymbol{B L}$ treatment.

The theory provides three possible reasons why high ability types choose Option 2 more frequently in the BL treatment than in the NI treatment: financial gains from teaching, non-pecuniary benefits from teaching, and benefits from social interactions. To separate these explanations, the NP treatment reduces the financial benefits from teaching while the NH treatment makes teaching much more difficult. In both cases, the proportion of high ability types choosing Option 2 is more than halved relative to the BL treatment ( $13 \%$ and $15 \%$ relative to $32 \%)$. Both differences are significant $(p=0.024$ for $\mathbf{N P}$ and $p=0.048$ for NH). The likelihood of choosing Option 2 is not significantly different for either of these treatments

\footnotetext{
${ }^{18}$ Every high ability type who chooses Option 1 in PR has a higher Heckman draw for Option 1 than Option 2.
} 
than in NI $(p=0.640$ for NP and $p=0.500$ for $\mathbf{N H})$, nor is the difference between the NP and NH treatments significant ( $p=0.830)$. Our fourth result follows.

Result 4: Consistent with $\mathbf{H 4}$, high ability types choose Option 2 less often in the $\mathbf{N P}$ treatment than in the $\boldsymbol{B L}$ treatment. Option 2 is also chosen less often in the $\mathbf{N H}$ treatment than in the $\boldsymbol{B L}$ treatment, but, contrary to $\mathbf{H 5}$, there is no difference between the $\mathbf{N P}$ and $\mathbf{N H}$ treatments.

Turning to the second dimension of our design, $\mathbf{H 6}$ predicts that Option 2 will be chosen more frequently in the Ice Breaker condition for all five primary treatments. Aggregating across all five primary treatments, Option 2 is chosen slightly less frequently by high ability types in the Ice Breaker condition (31\% vs. $25 \%$ ), but the difference is not significant $(p=0.314) .{ }^{19}$ Looking at the individual treatments, differences are generally small and not significant. ${ }^{20}$ One possible interpretation of the negligible effect of the Ice Breaker condition could be that it is too weak an intervention to affect the social distance between participants. Previewing results presented in Section 5.b, this seems unlikely since the Ice Breaker condition has powerful effects on the quantity of communication when subjects can chat. The Ice Breaker condition affects how teammates interact but does not affect their desire to join a team. This suggests that the financial implications of joining a team weigh more heavily in high ability types' minds than any social aspects. Result 5 summarizes our finding from the Ice Breaker condition.

Result 5: Contrary to H6, high ability types are not more likely to choose Option 2 in the Ice Breaker condition.

Thus far, we have used simple $\chi^{2}$ tests to determine the significance of differences between treatments. However, participants differ on a number of dimensions that could affect their choice, such as their own and partner's ability, the Heckman draws, and their personal characteristics. Table 3 reports the results of probit models that control for these factors. The dependent variable in all regressions is a dummy for the choice of Option 2. Probit models are used because the dependent variable is binary. The independent variables of greatest interest are the treatment dummies, with the BL treatment as the omitted category. All

\footnotetext{
${ }^{19}$ Low ability types are slightly more likely to choose Option 2 in the Ice Breaker condition (61\% vs. 63\%), but this difference is not significant $(p=0.807)$.

${ }^{20}$ The one exception is the $\mathbf{N H}$ treatment, where the choice of Option 2 is significantly lower in the Ice Breaker condition $(p=0.024)$. This is opposite of the predicted direction, but given that there is no reason to expect an effect to emerge in NH but not the other treatments, we are inclined to view it as a statistical anomaly.
} 
regressions include controls for the participant's own number of puzzles solved in Stage 1, their partner's number of puzzles solved in Stage 1, and the difference between the two Heckman draws divided by 10 (a positive difference means that Option 2 provides a higher guaranteed payoff than Option 1). Models $2 \mathrm{~L}$ and $2 \mathrm{H}$ include additional controls for personal characteristics: CRT score, age, and gender. These are not significant except for age in Model 2L. We report marginal effects rather than raw parameter estimates and robust standard errors in parentheses.

The estimated treatment effects are largely consistent with our previous observations. Looking at either Model $1 \mathrm{~L}$ or $2 \mathrm{~L}$, there are no significant treatment effects for low ability types. ${ }^{21}$ The negative and significant estimates for $\mathbf{N I}$ in Models $1 \mathrm{H}$ and $2 \mathrm{H}$ support $\mathbf{H 2}$, and the positive and significant estimates for PR support H3. The negative and significant parameter estimates for NP in Models $1 \mathrm{H}$ and $2 \mathrm{H}$ support H4. In line with Observation 4, the estimates for NH are negative. However, they are only marginally significant in Models $1 \mathrm{H}$ and $2 \mathrm{H}$. Contrary to $\mathbf{H 5}$, the estimates for $\mathbf{N P}$ and $\mathbf{N H}$ are not significantly different. The one detail that differs from our previous observations is the marginally significant negative effect of the Ice Breaker condition in Model 1H, contrary to the positive effect predicted in H6. However, the level of significance is low $(p=0.086)$ and falls below standard levels of significance in Model $2 \mathrm{H}$, suggesting that the Ice Breaker condition does not have a robust effect on the willingness of high ability types to join teams.

Comparing Models $1 \mathrm{~L}$ and $1 \mathrm{H}$, the response to differences in the Heckman draws is positive for both types, but significantly smaller for high ability types $(p=0.002) .{ }^{22}$ To understand this, notice that the expected difference between the two Heckman draws is only 33 Euro cents. This is a much lower share of Stage 1 earnings for high ability types (6\%) than low ability types (15\%). We suspect that low ability types respond more to the Heckman draws because the scale of payoffs looks relatively large to them.

\footnotetext{
${ }^{21}$ This would not change if we use a different treatment as the omitted category, since $\mathbf{B L}$ is the treatment where the fewest low ability types choose Option 2.

${ }^{22}$ To generate this $p$-stat, we took the specification from Models $1 \mathrm{H}$ and $1 \mathrm{~L}$, interacted all the variables with a dummy for high ability types, and ran a regression on the combined data from both types. The $p$-stat comes from the difference between the estimates for low and high ability types.
} 
Table 3: Probit Regressions on Choice of Option 2

\begin{tabular}{|c|c|c|c|c|}
\hline & \multicolumn{2}{|c|}{ Low Ability Types } & \multicolumn{2}{|c|}{ High Ability Types } \\
\hline & Model 1L & Model 2L & Model 1H & Model $2 \mathrm{H}$ \\
\hline Own, Stage 1 Correct & $\begin{array}{c}-0.077 * * * \\
(0.029)\end{array}$ & $\begin{array}{c}-0.083 * * * \\
(0.031)\end{array}$ & $\begin{array}{c}-0.052 \\
(0.041)\end{array}$ & $\begin{array}{c}-0.039 \\
(0.043)\end{array}$ \\
\hline Partner, Stage 1 Correct & $\begin{array}{c}0.010 \\
(0.048)\end{array}$ & $\begin{array}{c}0.015 \\
(0.049)\end{array}$ & $\begin{array}{c}0.016 \\
(0.025)\end{array}$ & $\begin{array}{c}0.019 \\
(0.023)\end{array}$ \\
\hline Difference, Heckman Draws & $\begin{array}{c}0.052 * * * \\
(0.009)\end{array}$ & $\begin{array}{c}0.052 * * * \\
(0.009)\end{array}$ & $\begin{array}{c}0.011 \\
(0.007)\end{array}$ & $\begin{array}{c}0.012 \\
(0.007)\end{array}$ \\
\hline PR & $\begin{array}{c}0.129 \\
(0.098)\end{array}$ & $\begin{array}{c}0.134 \\
(0.099)\end{array}$ & $\begin{array}{c}0.387 * * * \\
(0.097)\end{array}$ & $\begin{array}{c}0.394 * * * \\
(0.098)\end{array}$ \\
\hline NI & $\begin{array}{c}0.041 \\
(0.098)\end{array}$ & $\begin{array}{c}0.045 \\
(0.099)\end{array}$ & $\begin{array}{c}-0.209^{* * *} \\
(0.078)\end{array}$ & $\begin{array}{c}-0.205^{*} * * \\
(0.078)\end{array}$ \\
\hline NP & $\begin{array}{c}0.047 \\
(0.102)\end{array}$ & $\begin{array}{c}0.054 \\
(0.103)\end{array}$ & $\begin{array}{c}-0.193 * * \\
(0.079)\end{array}$ & $\begin{array}{c}-0.194 * * \\
(0.079)\end{array}$ \\
\hline NH & $\begin{array}{c}0.015 \\
(0.109)\end{array}$ & $\begin{array}{c}0.042 \\
(0.111)\end{array}$ & $\begin{array}{l}-0.154^{*} \\
(0.082)\end{array}$ & $\begin{array}{l}-0.153^{*} \\
(0.083)\end{array}$ \\
\hline Ice Breaker & $\begin{array}{l}-0.015 \\
(0.069)\end{array}$ & $\begin{array}{c}0.003 \\
(0.069)\end{array}$ & $\begin{array}{r}-0.107^{*} \\
(0.062)\end{array}$ & $\begin{array}{l}-0.101 \\
(0.064)\end{array}$ \\
\hline CRT Score & & $\begin{array}{c}0.029 \\
(0.033)\end{array}$ & & $\begin{array}{l}-0.013 \\
(0.033)\end{array}$ \\
\hline Age & & $\begin{array}{l}0.010^{*} \\
(0.006)\end{array}$ & & $\begin{array}{c}0.009 \\
(0.012)\end{array}$ \\
\hline Female & & $\begin{array}{l}-0.024 \\
(0.069) \\
\end{array}$ & & $\begin{array}{c}-0.082 \\
(0.066) \\
\end{array}$ \\
\hline Log-likelihood & -131.32 & -129.92 & -109.26 & -108.24 \\
\hline AIC & 280.64 & 283.85 & 236.52 & 240.47 \\
\hline $\mathrm{BIC}$ & 311.85 & 325.46 & 267.73 & 282.09 \\
\hline
\end{tabular}

Notes: All regressions are based on 237 observations. Marginal effects are reported. Robust standard errors are reported in parentheses. Three, two, and one stars indicate significance at the $1 \%, 5 \%$, and $10 \%$ levels, respectively.

It is arguable whether individuals are independent observations in the Ice Breaker condition since subjects interact prior to the beginning of the experiment. We treat individuals as independent observations since they do not know about the rest of the experiment when the ice breaker takes place, but an alternative version of Table 3 with the standard errors corrected for clustering can be found in Online Appendix 4 (Table A1), with a cluster defined as an individual in sessions without the ice breaker and defined as a session in sessions with the ice breaker. To address the broader possibility of session effects, Table A2 in Online Appendix 4 reports four versions of Model 1H. The first replicates the version shown in Table 3, the second corrects for clustering in sessions with the ice breaker (replicating the version shown in Table A1), the third corrects for clustering at the session level, and the fourth combines random effects at the session 
level with robust standard errors. None of our qualitative conclusions are affected by these different approaches to clustering in the data.

Summarizing our results thus far, the treatment effects suggest that the primary reason a sizable fraction of high ability types are willing to join teams in the $\mathbf{B L}$ treatment is the expected financial gain from teaching, especially from long-term improvement in their partners' productivity. If pro-social preferences play an important role, we should observe more high ability types choosing Option 2 in the NI, NP, and NH treatments. High ability types' answers to the post-experimental survey provide additional support for these conclusions. Subjects were given multiple possible reasons for their choice of options and could check as many reasons as they wanted. "Wanted to teach [my] partner" is the most common reason high ability types give for choosing Option 2 (see Table A3 in Online Appendix 4 for detailed statistics). This is especially true when teaching is most likely to have financial benefits (BL and $\mathbf{P R}$ ); teaching is more than twice as common (74\% vs. 33\%) than the second most frequent reason high ability types give for choosing Option 2 (“...thought communication would motivate [my] partner”). In contrast, when teaching is less likely to have financial benefits (NI, NP and NH), the reasons given for choosing Option 2 are mainly in line with some sort of pro-social preferences. About two-thirds of high ability types who choose Option 2 in these three treatments indicate they “... didn't want to let [their] partner down by not sharing revenue” and almost half state that they "... prefer to work with others." Neither of these reasons is common in the BL and PR treatments.

The point is not that the treatments affect the preferences of high ability types. Presumably, some high ability types with strong pro-social preferences are always willing to join a team regardless of the treatment. However, there appears to be a different and larger group of individuals who only join a team when it is likely to be financially beneficial. In the treatments where Option 2 is most likely to be financially beneficial due to teaching, most joiners identify teaching as their motivation. Result 6 summarizes this analysis.

Result 6: The ability to teach low ability types is the most common reason given by high ability types that choose Option 2, especially in treatments where teaching is likely to be financially beneficial (BL and PR). 
5.b. Do They Teach and Does It Help? High ability types frequently identify teaching their partner as a reason for choosing Option 2, but it need not follow that they actually provide help on how to solve the puzzles (i.e., try to teach) or that this improves their teammate's performance. This subsection addresses these two issues. To measure whether high ability types tried to teach, two research assistants independently coded all messages sent between teammates assigned Option 2 in BL, PR, NP, and NH. Details of how this coding exercise was conducted, including a full listing of the coding categories and frequencies for each category by treatment, are provided in Online Appendix 5. Here, we summarize the main results.

The theory is agnostic about how often help ought to be provided. There is no explicit cost to communication and no reason not to teach given that it is always potentially useful. Nonetheless, if there are effort costs involved with teaching, the pattern of when help is provided makes sense intuitively. Comparing the four treatments with chat, BL and PR make teaching relatively easy due to the hints and relatively beneficial due to the fixed partnership. High ability types send more messages per period in these two treatments (4.02 vs. 2.73) and give help with solving the puzzles more frequently (1.62 vs. 0.80). High ability types joining teams in these two treatments say they want to teach, and they do so.

The Ice Breaker condition does not affect the willingness of high ability types to choose Option 2, but it does increase the frequency of communication between teammates. The average total number of messages sent per period across the four treatments with chat increases in the Ice Breaker condition (7.33 vs. 5.60). The increase is similar for high (3.92 vs. 3.19) and low (3.42 vs. 2.41) ability types. The frequency of messages related to teaching by high ability types drops slightly in the Ice Breaker condition (1.72 vs. 1.49 in BL and PR). The Ice Breaker condition makes teammates more social, but has little effect on the amount of teaching.

Simple non-parametric tests are not useful for checking whether the differences reported above are significant, since treatment effects are confounded with selection into Option 2. We therefore run regressions with a Heckman correction for selection, using the Heckman draws and the random tie-breaker as instruments (see Online Appendix 5 for details and Table A5 for results). These regressions support our 
previous statements. High ability types send significantly more messages per period ${ }^{23}$ and send significantly more messages related to teaching per period ${ }^{24}$ in the $\mathbf{B L}$ and $\mathbf{P R}$ treatments compared to the $\mathbf{N P}$ and $\mathbf{N H}$ treatments. The Ice Breaker condition significantly increases messages per period for both types, ${ }^{25}$ but has no significant effect on the frequency of messages related to teaching by high ability types. ${ }^{26}$ This analysis is summarized by Result 7.

Result 7: High ability types communicate and teach more in the $\boldsymbol{B L}$ and $\boldsymbol{P R}$ treatments than in the $\boldsymbol{N P}$ and $\mathrm{NH}$ treatments. The Ice Breaker condition increases communication by both types, but does not affect the amount of teaching.

High ability types often try to teach low ability types, but it does not follow that teaching improves the performance of low ability types. A pre-condition for teaching to be effective is that the task is learnable. Comparing performance over time is tricky, as the difficulty of the puzzles varies widely. We solve this problem by using the same puzzles in Stages 2 and 3 and switching the rows and columns in Stage 3. Given this switch, the five period gap between repetitions, and the lack of any way to view previous puzzles, it is highly unlikely that participants notice the repetition. Comparing performance in Stages 2 and 3 gives a clean test of whether learning is possible. The average number of puzzles solved increases significantly from 2.96 in Stage 2 to 3.36 in Stage $3(p<0.0001),{ }^{27}$ with similar increases for both types $(2.59 v s .3 .06$ for low ability types; $3.33 v s .3 .65$ for high ability types). Subjects learn between Stages 2 and 3 .

The regressions shown in Table 4 examine the effect of messages relating to teaching on the number of puzzles solved in Stage 3. We correct for selection using a Heckman correction as described previously. The dependent variable is the number of puzzles solved in Stage 3, after teaching has occurred. We focus on three independent variables: the total number of Stage 2 codings for the high ability type giving help, the low ability type asking for help, and the high ability type specifically referring to the hints. These three categories directly relate to high ability types teaching low ability types. The regressions include additional

\footnotetext{
${ }^{23}$ The coefficient is 1.292 with a robust standard error of $0.339(p<0.001)$.

${ }^{24}$ The coefficient is 0.742 with a robust standard error of $0.221(p<0.001)$.

${ }^{25}$ For low (high) ability types, the coefficient is $1.123(0.969)$ with a robust standard error of $0.301(0.350)$. In both cases, $p<0.01$.

${ }^{26}$ The coefficient is -0.045 with a robust standard error of $0.224(p=0.842)$.

27 This is based on a Wilcoxon matched-pairs signed-ranks test with each session treated as a single observation.
} 
unreported controls for the treatment, own ability, and teammate's ability.

For low ability types, a powerful negative effect from high ability types giving help is offset by the positive effect of referring to the hints. Receiving help never improves the performance of low ability types but is harmful only if the hints are not used. We conjecture that this reflects two countervailing forces: help based on the hints contains useful information but is also a distraction for the low ability types. ${ }^{28}$

Table 4: Effects of Teaching on Performance

\begin{tabular}{ccc}
\hline & Low Ability & High Ability \\
\hline High Ability Type Gives Help & $-0.129 * * *(0.041)$ & $-0.029(0.040)$ \\
\hline Low Ability Type Requests Help & $-0.037(0.057)$ & $-0.046(0.052)$ \\
\hline High Ability Type Refers to Hints & $0.111^{* * *}(0.042)$ & $0.088 * *(0.043)$ \\
\hline Log-likelihood & -227.31 & -233.19 \\
AIC & 486.62 & 498.39 \\
BIC & 538.32 & 550.08
\end{tabular}

Notes: These regressions are based on 187 observations, including 107 participants assigned to Option 2, and use a Heckman correction. Robust standard errors are reported in parentheses. Three, two, and one stars indicate significance at the $1 \%, 5 \%$, and $10 \%$ level, respectively.

In contrast, providing help (i.e. teaching) by using the hints improves the performance of the high ability types in Stage 3. Presumably using the hints to teach allows high ability types to better organize their reasoning and think more carefully than would occur otherwise, making high ability types better at solving the puzzles. This observation is consistent with several studies in educational and cognitive psychology which document that teaching has cognitive benefits (the "protégé effect"), notably by fostering selfregulatory processes (e.g., Bargh and Schul, 1980; Leelawong and Biswas, 2008; Nestojko et al., 2014; Muis et al., 2016; Koh et al., 2018).

The data suggest that high ability types primarily join teams because they anticipate benefits from teaching low ability types. They are correct to anticipate these benefits, but in a presumably unanticipated fashion. Rather than improving the performance of their teammate, teaching primarily improves the

\footnotetext{
${ }^{28}$ We did not give the hints directly to the low ability players, so we have no evidence on whether the hints themselves would be as effective for them as for high ability participants. The minimal impact of receiving teaching with hints could reflect a low value of hints for low ability participants or poor teaching by high ability participants; our design does not make it possible to separate these two possibilities.
} 
performance of the high ability type doing the teaching. This leads to our eighth result.

Result 8: Being taught does not improve the performance of low ability types and can harm performance when teaching is not based on the hints. Teaching by using the hints improves the performance of high ability types.

5.c. Does Choosing Option 2 Improve Payoffs? If high ability types choose Option 2 because of higher anticipated financial benefits, there should be a positive relationship between the likelihood of choosing Option 2 and the expected payoff. Table 5 reports average total payoffs across Stages 2 and 3 (excluding the Heckman draws) for high ability types, broken down by whether the individual is assigned to Option 1 or $2 .^{29}$ Because it is endogenous which participants are assigned to Option 2, we complement the raw data shown in Table 5 with IV regressions. For each treatment, these regress total payoffs on assignment to Option 2, using the Heckman draws and random tie-breaker as instruments for assignment to Option 2, and controlling for ability and the Ice Breaker condition. The estimated difference (i.e., the estimated effect of being assigned to Option 2) and $p$-values reported in Table 5 come from these regressions.

Table 5: Average Payoffs for High Ability Types in Stages 2 and 3

\begin{tabular}{cccc}
\hline & Option 1 & Option 2 & Estimated Difference $(p$-value $)$ \\
\hline BL & 8.33 & 7.61 & $0.342(0.480)$ \\
PR & 7.97 & 8.77 & $1.447(0.022)$ \\
NI & 8.73 & 7.68 & $-0.702(0.421)$ \\
NP & 8.77 & 7.83 & $-1.453(0.081)$ \\
NH & 8.09 & 7.83 & $-0.408(0.496)$ \\
\hline
\end{tabular}

The pattern of estimated gains lines up well with the frequency of choosing Option 2: high ability types are most likely to choose Option 2 in $\mathbf{P R}$, the treatment with the highest estimated (and only significant) gain from choosing Option 2. The only other treatment that generates a substantial number of high ability types choosing Option 2 is $\mathbf{B L}$, which is also the only other treatment where the estimated benefit is positive. The three treatments where a negligible number of high ability types choose Option 2 (NI, NP, and NH) all have negative estimated benefits from choosing Option 2. The pattern of choices correlates well with expected financial benefits from choosing Option 2, leading to our final result.

\footnotetext{
${ }^{29}$ Recall that the option a participant is assigned need not be the same as the option that they choose. Table A6 in Online Appendix 5 reports analogous results for the number of puzzles solved in Stages 2 and 3.
} 
Result 9: For high ability types, there is a positive relationship between the estimated benefits of being assigned Option 2 and the likelihood of choosing Option 2.

We conclude the results section with a brief discussion of a critical question from a manager's point of view: Is it beneficial to adopt revenue sharing? To answer this question, we compare the total number of puzzles solved across Stages 2 and 3 for teams assigned to Option 2 in the BL and PR treatments. These two treatments differ solely in how participants are paid for Stage 2. Given that the total pay per puzzle solved is the same in both treatments, productivity directly determines a manager's profits. Total output rises from 12.29 in $\mathbf{B L}$ to 13.38 in $\mathbf{P R}$ (Wilcoxon rank-sum test, $p=0.078$ ). Although it is not our aim to study the relative merit of revenue sharing, the somewhat lower productivity in BL illustrates the potential downside of revenue sharing.

6. Discussion and Conclusion: Team production and team incentives are pervasive within organizations. While there are good reasons for this, such as taking advantage of complementarities in production and encouraging mutual monitoring, adverse selection is likely to limit the advantages of teams. This might explain the coexistence of several forms of work organization across sectors and across firms within the same sector. For example, data from the European Working Conditions Survey EWCS 2000/2001 about the incidence of teamwork show a higher proportion of employees working in teams in large enterprises with 250 employees or more and in industrial sectors (about 65\% in the 15 main EU countries), while lower proportions are registered in the construction industry and in services (61.6\%); in a survey of US organizations, $48 \%$ of the respondents indicated that their organization used some type of team, with a higher incidence in more complex and larger organizations (Denine et al., 1999). Better knowledge of the selection process into teams is a necessary ingredient for understanding when teams will be beneficial and how to design team incentives. Relatively little research exists which examines workers' willingness to join teams. Laboratory experiments, like those presented in this study, are a useful complement to field studies because the controlled environment makes it possible to isolate specific reasons for joining a team.

We study a stark environment that eliminates the most obvious reasons that a high ability worker would want to join a revenue sharing team, such as complementarities in production. Nevertheless, we find that 
roughly a third of high ability workers are willing to join revenue sharing teams in our Baseline treatment. Additional treatments indicate that this willingness of high ability types to join revenue sharing teams stems from expected financial benefits rather than pro-social preferences, specifically long-term gains from teaching their low ability partners. A post-experimental survey supports this conclusion as wanting to teach their partner is the most common reason given by high ability types for joining a team.

When assigned to a team, high ability types frequently provide help to their low ability partner as long as it is straightforward to do so by using the hints. Teaching improves productivity, but it does so in an unexpected fashion. Rather than increasing the performance of low ability types, teaching by using the hints helps the performance of high ability types. It is possible that, to be more effective, the teaching of less able performers requires more time than permitted in the context of a short experiment.

The importance of teaching as a motivation to join a team is consistent with the correlation observed in the European Working Conditions Survey 2000/2001 between the incidence of teamwork and working in an environment associated with the possibility to learn new things, to perform complex tasks, and to benefit from training paid for by the employer (Kylinkova et al., 2007). An interesting extension of our study would be to investigate whether posting job offers that emphasize teaching and learning opportunities associated with teamwork would attract more applications and from better skilled candidates than equivalent job offers with no emphasis on learning.

Our results indicate no effect of the Ice Breaker manipulation on the choice of joining a team although the content of communication during the game was richer in this condition. This contrasts with previous studies showing that socialization increases effort both in team-based tournaments because of guilt aversion (Chen and Lim, 2013) and in teams under group incentives (Lim and Chen, 2014). The difference with our results may derive from the fact that in these two studies, subjects introduced themselves to one another in small groups of four. Moreover, in Lim and Chen (2014), they communicated face-to-face for one minute with their partner before making each effort decision. These differences could have decreased social distance, although the face-to-face communication prior to the effort decision also enabled peer pressure and non-pecuniary punishment. Another possibility is that the results differ because our experiment is 
primarily about the choice of payment scheme, and the role of effort is intentionally minimized. Part of why we are interested in exploring how our findings generalize to settings with costly effort is that the Ice Breaker condition might have more impact when effort has more of a role.

Our conclusions are based on the results of an experiment that represents a specific environment. The task is artificial along several dimensions: effort plays a minimal role in performance compared to ability, there are no direct complementarities in production, and quitting is not allowed. Our goal was to study why high ability workers might join teams in the absence of immediate financial benefits; we purposefully chose a simple environment with clear tradeoffs between short-term financial losses and possible gains due to teaching. With these caveats, our results suggest that in real-world settings managers should be aware of the negative effects of adverse selection when considering adoption of revenue sharing teams since their organizations may become less attractive to the ablest workers. On a brighter note, however, our findings also suggest that these effects can be mitigated by designing a work environment that makes it possible for high ability types to successfully teach their less skilled co-workers and subsequently reap the rewards of teaching. This includes the provision of tools that facilitate teaching and clear incentives that encourage the transmission of knowledge that is key for the development of collective intelligence in organizations.

A natural line of future research is to examine how our findings generalize to more realistic settings that include elements such as direct complementarities in production, effort costs, and quitting. Online Appendix 3 extends the model to include direct complementarities. The extended model predicts that increasing either the possibility of teaching or the degree to which workers' efforts are complements makes it more likely that high ability types will want to join a team, but does not predict which effect is larger. The relative size of the effects depends on the degree to which teaching is effective, which is an empirical question rather than a theoretical one. Experiments that exogenously vary whether there are direct complementarities in production and the efficacy of teaching would shed some light on the relative importance of direct complementarities versus teaching, as well as illuminating the interaction between these two factors. Another interesting extension would be to let players choose whether to quit their team 
prior to Stage 3. This would let us study how the choice to join a team in Stage 2 is affected by the ability to revisit their decision prior to Stage 3, and inform us about the interactions between teaching and mobility. 


\section{References}

Ahn, T. K., R. Mark Isaac, and Timothy C. Salmon (2008). Endogenous group formation. Journal of Public Economic Theory 10(2), 171-194.

Alchian, Armen A., and Harold Demsetz (1972). Production, Information Costs, and Economic Organization. American Economic Review 62(5), 777-795.

Babcock, Philip, Kelly Bedard, Gary Charness, John Hartman, and Heather Royer. (2015). Letting Down the Team? Social Effects of Team Incentives. Journal of the European Economic Association 13(5), 841-870.

Bäker, Agnes, and Vanessa Mertins (2013). Risk-sorting and preference for team piece rates. Journal of Economic Psychology 34, 285-300.

Bandiera, Oriana, Iwan Barankay, and Imran Rasul (2013). Team Incentives: Evidence from a Firm Level Experiment. Journal of the European Economic Association 11(5), 1079-1114.

Bargh, John A., and Yaacov Schul (1980). On the cognitive benefits of teaching. Journal of Educational Psychology 72(5), 593-604.

Blasco, Andrea, Kevin J. Boudreau, Karim R. Lakhani, Michael Menietti, and Christoph Riedl (2013). Do Crowds have the Wisdom to Self-Organize? Mimeo.

Bolton, Gary E., and Axel Ockenfels (2000). ERC: A theory of equity, reciprocity, and competition. American Economic Review 90(1), 166-193.

Calsamiglia, Caterina, Jörg Franke, and Pedro Rey-Biel (2013). The incentive effects of affirmative action in a real-effort tournament. Journal of Public Economics 98, 15-31.

Charness, Gary, and Peter Kuhn (2011). Lab Labor: What Can Labor Economists Learn from the Lab? In Orley Ashenfelter and David Card (Eds.), Handbook of Labor Economics, Volume 4A, Amsterdam: North-Holland, 229-330.

Charness, Gary, and Matthias Sutter (2012). Groups make better self-interested decisions. Journal of Economic Perspectives, 26(3), 157-76.

Charness, Gary, and Chun-Lei Yang (2014). Starting small toward voluntary formation of efficient large groups in public goods provision. Journal of Economic Behavior \& Organization 102, 119-132.

Chaudhuri, Ananish (2011). Sustaining cooperation in laboratory public goods experiments: a selective survey of the literature. Experimental Economics 14(1), 47-83.

Chen, Hua, and Noah Lim (2013). Should Managers Use Team-Based Contests? Management Science 59(12), 2823-2836.

Chen, Roy (2017). Coordination with Endogenous Groups. Journal of Economic Behavior \& Organization $141,177-187$.

Chen, Roy, and Jie Gong (2018). Can self selection create high-performing teams? Journal of Economic Behavior \& Organization 148, 20-33.

Chen, Yan, and Sherry Xin Li (2009). Group identity and social preferences. American Economic Review 99(1), 431-57.

Cooper, David J., and Krista J. Saral (2013). Entrepreneurship and team participation: An experimental study. European Economic Review 59, 126-140.

Czibor, E., Rosendahl Huber, L., Koudstaal, M., (2017). Are entrepreneurs lone wolves? An experimental analysis of sorting into teams. Working paper. 
Denine, Dennis J., Laura D. Clayton, Jennifer J. Philips, Benjamin B. Dunford, and Sarah B. Melner (1999). Teams in organizations: Prevalence, Characteristics, and Effectiveness. Small Group Research 30(6), $678-711$.

Dohmen, Thomas, and Armin Falk (2011). Performance Pay and Multidimensional Sorting: Productivity, Preferences, and Gender. American Economic Review 101(2), 556-590.

Dostie, Benoit (2015). Who benefits from firm-sponsored training? IZA World of Labor 145.

Drago, Robert, and Gerald T. Garvey (1998). Incentives for Helping on the Job: Theory and Evidence. Journal of Labor Economics 16(1), 1-25.

Fehr, Ernst, and Klaus M. Schmidt (1999). A theory of fairness, competition, and cooperation. The Quarterly Journal of Economics 114(3), 817-868.

Fischbacher, Urs (2007). z-Tree: Zurich toolbox for ready-made economic experiments. Experimental Economics 10(2), 171-178.

Frederick, Shane (2005). Cognitive reflection and decision making. Journal of Economic Perspectives $19(4), 25-42$.

Greiner, Ben (2015). Subject pool recruitment procedures: organizing experiments with ORSEE. Journal of the Economic Science Association 1(1), 114-125.

Hamilton, Barton, Jack Nickerson, and Hideo Owan. (2003). Team Incentives and Worker Heterogeneity: An Empirical Analysis of the Impact of Teams on Productivity and Participation. Journal of Political Economy 111(3), 465-497.

Holmström, Bengt (1982). Moral Hazard in Teams. Bell Journal of Economics 13(2), 324-40.

Hoogendoorn, Sander, Simon C. Parker, and Mirjam van Praag (2014). Ability Dispersion and Team Performance. Tinbergen Institute Discussion Paper 14-053/VII.

Ichniowski, Casey, Kathryn Shaw, and Giovanna Prennushi (1997). The effects of human resource management practices on productivity: A study of steel finishing lines. American Economic Review 87(3), 291-313.

Ichniowski, Casey, and Kathryn Shaw (1999). The Effects of Human Resource Management Systems on Economic Performance: An International Comparison of U.S. and Japanese Plants. Management Science 45(5), 704-721.

Itoh, Hideshi (1991). Incentives to help in multi-agent situations. Econometrica 59(3), 611-636.

Kyzlinková, Renáta, Lenka Dokulilová, and Aleš Kroupa (2007). Teamwork and high performance work organization. European Foundation for the Improvement of Living and Working Conditions Luxembourg, Office for Official Publications of the European Communities. https://www.eurofound.europa.eu/publications/article/2007/teamwork-and-high-performance-workorganisation. Retrieved 27 April 2020.

Kimbrough, Erik O., Andrew D. McGee, and Hitoshi Shigeoka (2017). How Do Peers Impact Learning? An Experimental Investigation of Peer-to-Peer Teaching and Ability Tracking. NBER Working Paper 23439.

Kocher, Martin, Sabine Strauß, and Matthias Sutter (2006). Individual or team decision-making: causes and consequences of self-selection. Games and Economic Behavior 56(2), 259-270.

Koh, Aloysius Wei Lun, Sze Chi Lee, and Stephen Wee Hun Lim (2018). The learning benefits of teaching: A retrieval practice hypothesis. Applied Cognitive Psychology 32(3), 401-410.

Kosfeld, Michael, and Ferdinand von Siemens (2009). Worker self-selection and the profits from cooperation. Journal of the European Economic Association 7(2-3), 573-582. 
Kuhn, Peter, and Marie Claire Villeval (2015). Are women more attracted by cooperative work environments? Economic Journal 125(582), 115-140.

Lazear, Edward (1999). Globalisation and the market for team-mates. Economic Journal 109(454), 15-40.

Lazear, Edward (2000). Performance pay and productivity. American Economic Review 90(5), 1346-1361.

Lazear, Edward P., and Kathryn L. Shaw (2007). Personnel Economics: The Economist's View of Human Resources. Journal of Economic Perspectives 21(4), 91-114.

Lawler, Edward E., III, Susan A. Mohrman, and George Benson (2001). Organizing for high performance: employee involvement, TQM, reengineering, and knowledge management in the Fortune 1000. San Francisco: Jossey-Bass.

Lawler, Edward E., III, and Susan A. Mohrman (2003). Pay Practices in Fortune 1000 Corporations. Center for Effective Organizations, G 03-20 (448).

Leelawong, Krittaya, and Biswas, Gautam (2008). Designing learning by teaching agents: The Betty's brain system. International Journal of Artificial Intelligence in Education 18(3), 181-208.

Lim, Noah, and Hua Chen (2014). When Do Group Incentives for Salespeople Work? Journal of Marketing Research 51(3), 320-334.

List, John, and Imran Rasul (2011). Field Experiments in Labor Economics. In Orley Ashenfelter and David Card (Eds.), Handbook of Labor Economics, Volume 4A, Amsterdam: North-Holland, 104-228.

Meidinger, Claude, Jean-Louis Rullière, and Marie Claire Villeval (2003). Does team-based compensation give rise to problems when agents vary in their ability? Experimental Economics 6(3), 253-272.

Muis, Krista R., Cynthia Psaradellis, Marianne Chevrier, Ivana Di Leo, and Susanne P. Lajoie, (2016). Learning by preparing to teach: Fostering self-regulatory processes and achievement during complex mathematics problem solving. Journal of Educational Psychology 108(4), 474-492.

Nestojko, John F., Dung C. Bui, Nate Kornell, and Elizabeth Ligon Bjork (2014). Expecting to teach enhances learning and organization of knowledge in free recall of text passages. Memory \& Cognition 42, 1038-1048.

Oosterhof, Aad, Gerben S. Van der Vegt, Evert Van de Vliert, and Karin Sanders (2009). Valuing Skill Differences: Perceived Skill Complementarity and Dyadic Helping Behavior in Teams. Group \& Organization Management 34(5), 536-562.

Owan, Hideo (2014). How should teams be formed and managed? IZA World of Labor 83.

Villeval, Marie Claire (2020). Public goods, norms and cooperation. Forthcoming in C. Monica Capra, Rachel Croson, Mary Rigdon, and Tanya Rosenblat (Eds.), Handbook of Experimental Game Theory, Cheltenham, UK and Northampton, MA, USA: Edward Elgar Publishing.

Wozniak, David, William T. Harbaugh, and Ulrich Mayr (2014). The menstrual cycle and performance feedback alter gender differences in competitive choices. Journal of Labor Economics 32(1), 161-198.

Wuchty, Stefan, Benjamin F. Jones, and Brian Uzzi (2007). The Increasing Dominance of Teams in Production of Knowledge. Science 316(5827), 1036-1039. 


\section{ONLINE APPENDIX 1: INSTRUCTIONS}

\section{[All treatments]}

Thank you for participating in today's experiment. I will read the instructions that explain the content of today's experiment and the interfaces. Feel free to ask questions if you have any.

You will receive 4 Euros for showing up on time for the experiment. In addition, you will be able to earn money during the experiment and in a final questionnaire. At the end of the experiment, you will be called individually to receive your earnings in private. The amount you will have earned will be paid in cash. If you have any questions, press the red button on the side of your desk and we will answer your questions in private.

\section{[Ice Breaker condition]}

PRELIMINARY PART

The purpose of this preliminary part is to help you get to know other participants in today's session. You have received a form to complete that includes a set of individual characteristics.

Your objective is to complete a line OR a column OR a diagonal of four cells with the signatures of other participants in the session that correspond to the characteristics described by these cells.

A person can sign only one cell on a card and you cannot sign your own form. There is no need to put your name on the cells or on the form.

We will therefore ask you to get up and go into the reception room to exchange your information and fill your form.

Once you have completed four cells (on a line, or a column or a diagonal) with four signatures, please return your form to an experimenter and return to your seat.

--- After subjects come back to their seats----

Please press the Continue button and follow the instructions on your screen.

\section{[All treatments]}

\section{PART 1}

This part consists of 5 periods, each consisting of a puzzle to solve. In each period you will have 90 seconds to solve the puzzle. If you solve the puzzle correctly before the time runs out, you will earn $€ 1.25$. Otherwise, you will earn $€ 0$ for this period.

Press Continue to see an example of a puzzle to solve. 


INSTRUCTIONS
Vous pouvez voir à l'écran un puzzle avec des carrés que
vous allez devoir noircir ou laisser vides (blanc).
A côté de chaque ligne et au-dessus de chaque colonne
du puzzle on vous indique la longueur des séries de
carrés noirs de la ligne ou de la colonne.
Le but est de trouver tous les carrés noirs avant la fin du
temps imparti.
Cliquez sur le carré pour le faire devenir noir. Vous
pouvez verifier votre réponse en cliquant sur le bouton en
dessous du puzzle.
Gous gagnerez $1.25 €$ si vous résolvez correctement le
puzzle.

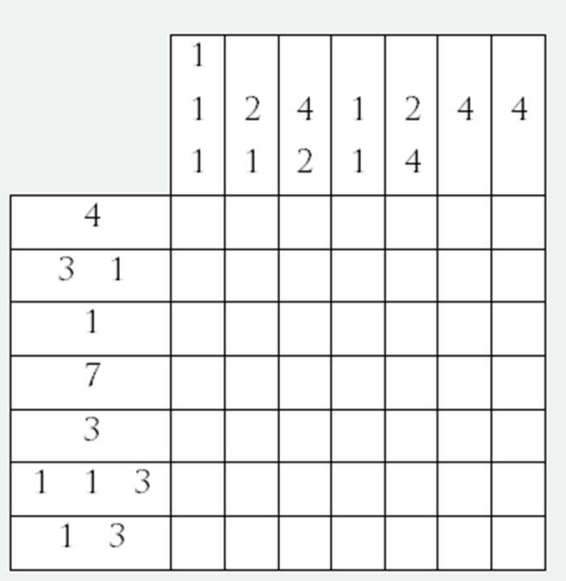

Cliquer sur « Vérifier Réponse » pour voir si vous avez correctement résolu le puzzle

Vérifier Réponse

You should now have on your screen the interface of the puzzle that you will see throughout the experiment. The type of puzzle you will have to solve is called a nonogram. The rules are simple. You can see a grid of squares that you have to blacken or leave blank. Click on the square to blacken it and click again to make it white again.

Beside each line of the puzzle, we indicate the length of each series of black squares in this line, in order. Above each column we indicate the length of each series of black squares in that column, in order. The goal is to find and mark all the black squares.

For example, next to the first line of the grid, you can see the number 4. This means that there is a series of 4 black squares, with no spaces between them, in the first line.

In some cases, there may be more than one number. For example, in the second line, you can see the numbers 3 and 1 . This means that in this line, there is a series of exactly 3 black squares, followed by one or more white squares, followed by a single black square.

Columns work the same way as rows. In the first column you can see the numbers 1,1 and 1 , which means that there are three isolated black squares in this column and there must be at least one white square between each black square.

While you are trying to solve the puzzle, you can press the "Check Answer" button at any time to see if you have successfully solved the puzzle. You can continue making changes in the grid once you have pressed this button. You will have 90 seconds in total to solve this puzzle and at the end of the allotted time, you will be automatically redirected to the results screen. 
Please press Continue to be redirected to an example of the results screen.

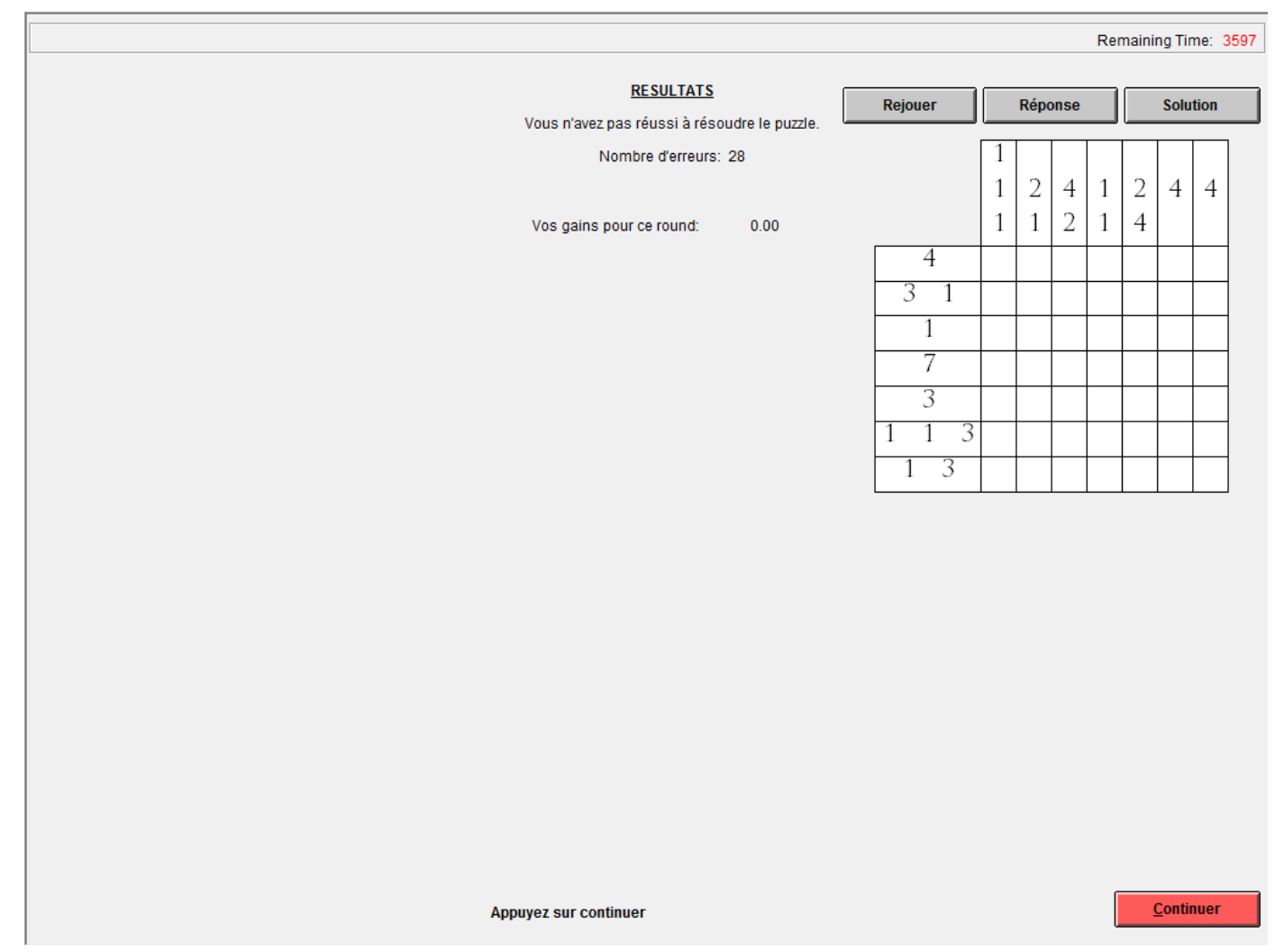

You can now see an example of a results screen to which you will be redirected at the end of each period. In the middle of the screen you can see if you have solved the puzzle or not. If you have not succeeded, you are informed of your number of errors. As this is a training period, there are no earnings, but if this period had been paid, you would have earned $€ 1.25$ if you had solved the puzzle before time had run out.

Above the grid on the right, you can choose "Replay," which allows you to review the markings you have made in the previous screen. Errors are indicated by a red X. You can also pause this by pressing the red "Pause" button that will appear after you press Replay.

You can also see your answer without reviewing all the markings made by pressing the "Answer" button or simply look at the solution by pressing the "Solution" button. Please press the Solution button. You can now see that the grid is immediately updated with the solution of the puzzle. You now have 3 minutes to look at this solution.

\section{3 minutes}

\section{SUMMARY OF PART 1}

- This part consists of 5 periods of the game you just saw.

- In each period you will have 90 seconds to solve a puzzle.

- At the end of the allotted time, you will automatically see the results screen where you can review your answers for 60 seconds before starting the next period. 
At the end of the 5 periods, you will receive summary information about the number of puzzles you have solved and the results of the other participants.

We will now start the paid periods. Please press Continue to start the first period.

[ BL treatment (revenue sharing, interactions, hints and same partner in the last part)]

\section{PART 2}

You have now completed Part 1. Please press Continue.

Before you start the second part, you should know that participants in the session ranked in the top half in terms of the number of solved puzzles (i.e., those who solved more puzzles than the median) have been selected to receive hints.

If you have been selected, you should now see the hints displayed in the center of your screen. These hints will always be accessible until the end. If you have not been selected, this is indicated at the top of your screen.

We have also distributed a sheet of paper to each of you. If you have received hints, the sheet gives a more detailed description of these hints. If you have not received hints, the sheet has only an empty frame that you can complete.

Please do not press Continue until you have received your sheet of paper. Take time to look at this sheet. Then press Continue to see the new rules for this part.

\section{3 minutes}

A new part is about to start with different rules. In this part you will participate in the same game for another 5 periods, but in this part you will be paired with a partner. You will keep the same partner for the 5 periods.

If you received hints, your partner did not receive them and conversely, if you did not receive hints, your partner received them. At the bottom of the screen, you can see information about your performance and that of your partner in the first part.

Please press Continue.

In each period, you and your partner will have to solve the same puzzle individually, but you have the choice on how to participate in this part with your partner. You have to choose one of the following two options that will apply to the 5 periods. The differences between the options are highlighted in red on your screen.

Option 1 appears in the box on the left of your screen.

\section{With option 1:}

- You will earn $€ 1.25$ for each puzzle solved by yourself. 
- At the end of each period, you will receive the same feedback as before but you will also see information about your partner's puzzle and results and vice versa.

Option 2 appears in the box on the right of your screen.

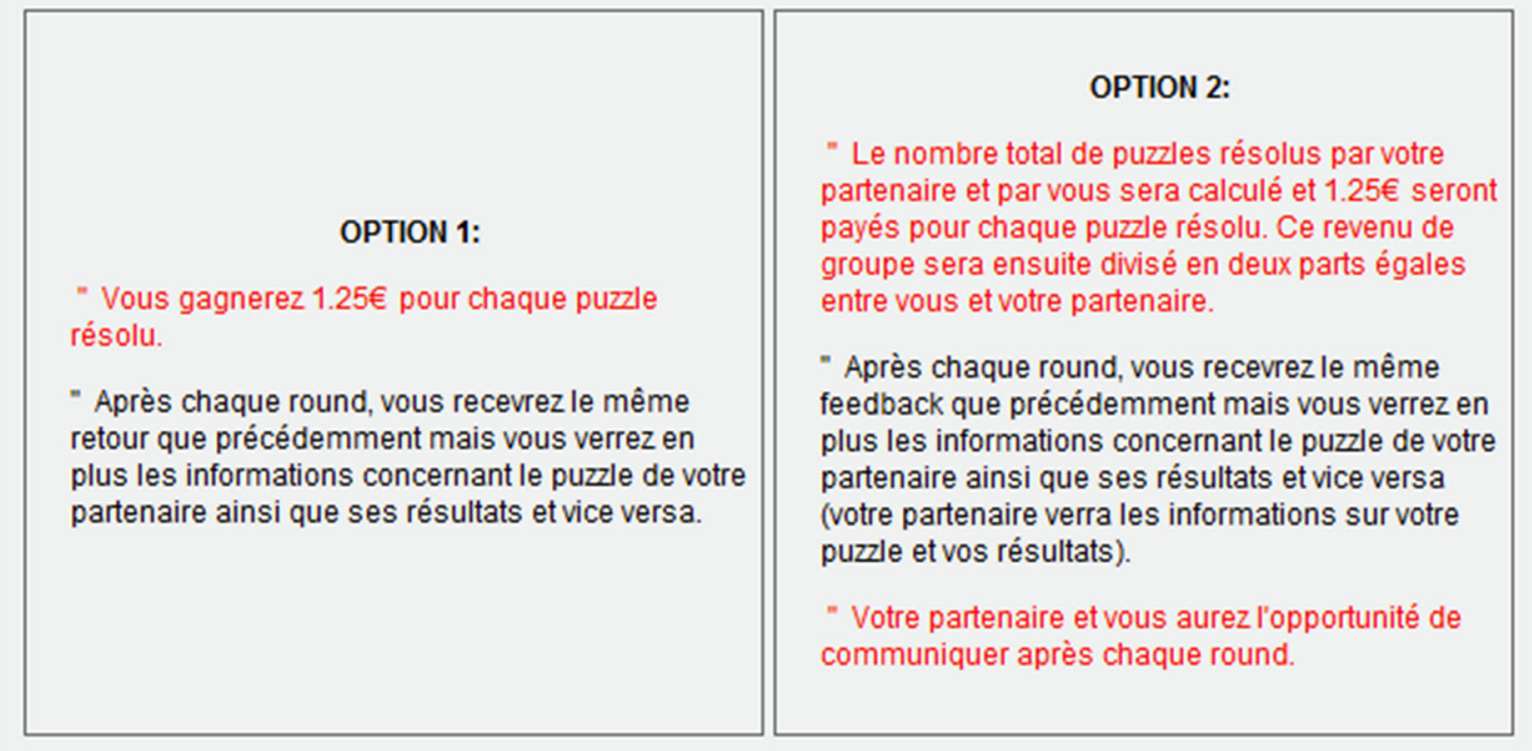

\section{With option 2:}

- The total number of puzzles solved by your partner and by you will be calculated and $€ 1.25$ will be paid for each puzzle solved. This group income will then be divided in two equal parts between you and your partner.

- After each round, you will receive the same feedback as before but you will also see information about your partner's puzzle and results and vice versa.

- Your partner and you will have the opportunity to communicate after each round.

Note that the difference between these options is that you will be able to communicate with your partner and you will share your earnings with your partner in option 2, but not in option 1. Any interaction is done on the results screen only, and not while you are trying to solve the puzzle.

Please press Continue to see how the interface changes depending on the option. 
ECRANS DE JEU

Les images suivantes montrent l'écran que vous verrez durant le jeu. Si vous avez choisi l'option 2 , vous verrez une information supplémentaire concernant la structure de partage des gains.

Option 1

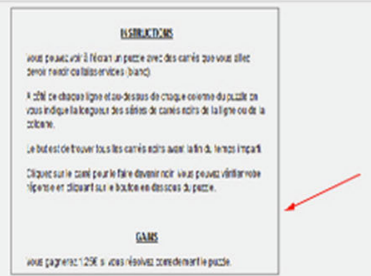

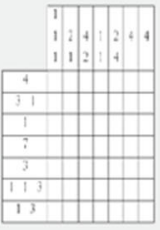

Option 2
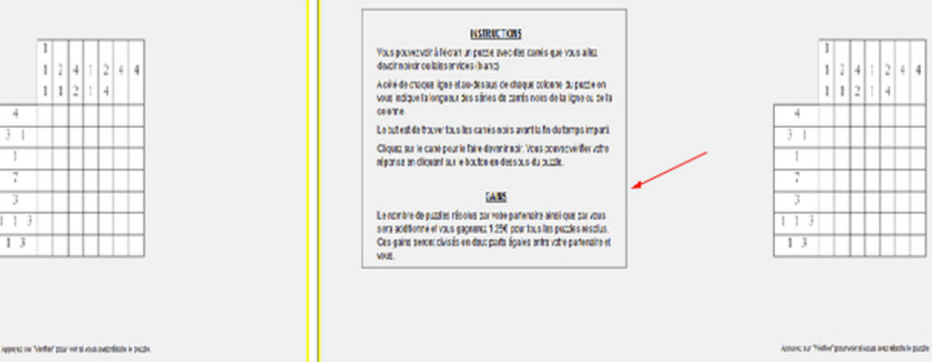

回

The figures show a side-by-side comparison of the screens for both options. Whichever option you have chosen, the screen is identical and it is identical to previous periods. The red arrows point to the difference in the earnings but everything else is similar. You and your partner must solve the puzzle individually. If you have been selected to receive hints, you will have access to them at the bottom left of your screen.

Please press Continue. 


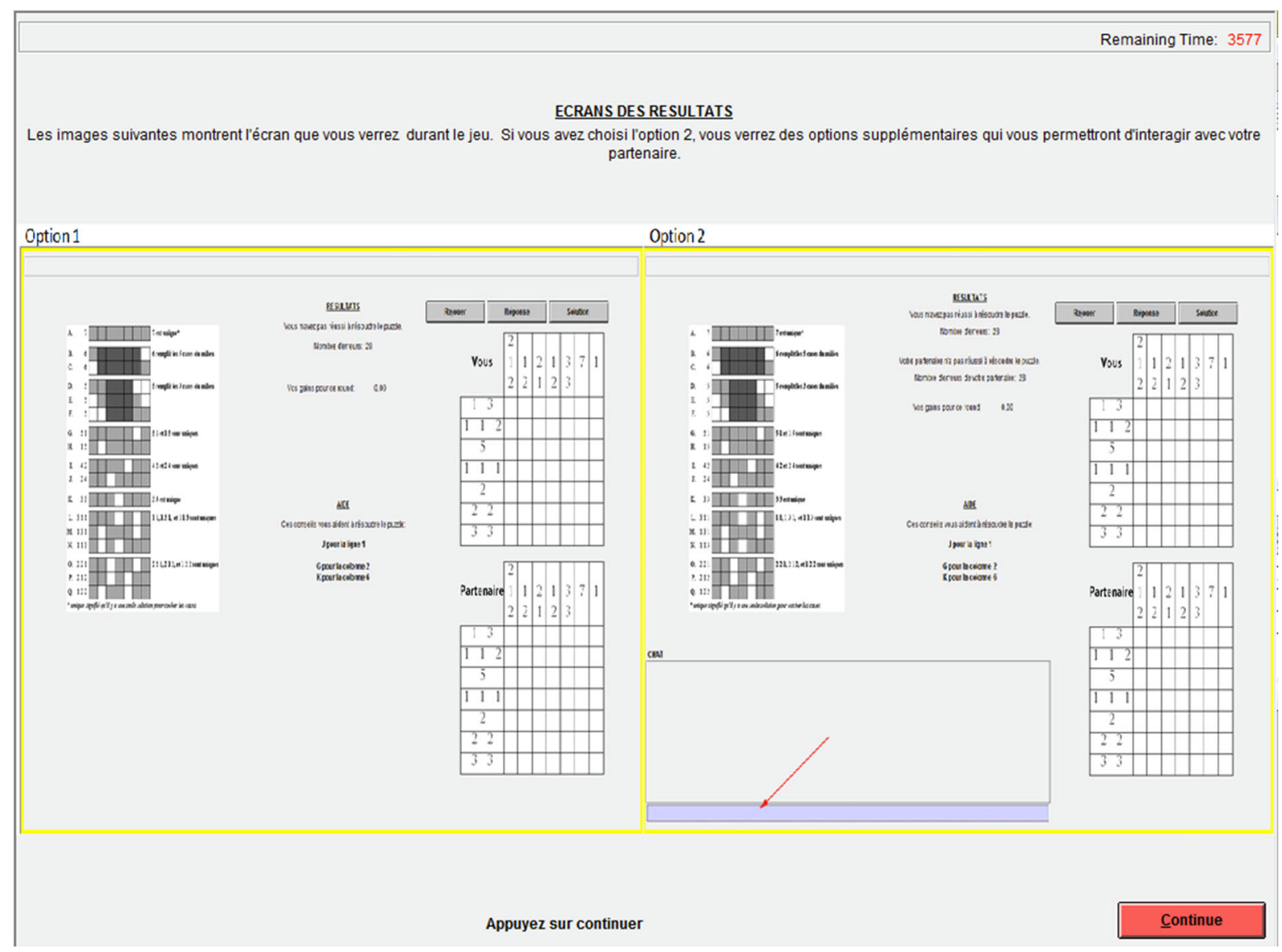

You should now see a side-by-side comparison of the results screens for both options.

In each option, you will receive information about your partner's puzzle in the middle of the screen, below your own results.

The main differences between option 1 and option 2 have been highlighted with red arrows. For option 1 , the results screen is the same as in the previous part. For option 2, the screen allows you to interact with your partner.

- First, you will also have access to your partner's grid on the right. So, when you choose Replay or Solution or Answer, it will update with your answer at the top and your partner's answer at the bottom. This is also valid for your partner who will also have access to your results.

- Second, you can freely exchange messages with your partner by writing inside the chat box at the bottom of your screen.

You can use the chat box to talk about what you want, including the information on the hints if you received them. The only restriction is that you must not try to identify yourself or use offensive language.

Please press Continue.

You are informed that in the third and last part, you will remain matched with the same partner as in this second part. But while in this second part you have the choice of the mode of participation with your partner, in the last part:

- you will not have the choice of the option 
- you and your partner will no longer have the opportunity to interact

- and $€ 1.25$ will be paid for the sum of the puzzles solved by your partner and by you. This group income will then be divided in two equal parts between you and your partner.

Please press Continue.

[PR treatment (piece rate, interactions, hints and same partner in the last part)]

\section{PART 2}

You have now completed Part 1. Please press Continue.

Before you start the second part, you should know that participants in the session ranked in the top half in terms of the number of solved puzzles (i.e., those who solved more puzzles than the median) have been selected to receive hints.

If you have been selected, you should now see the hints displayed in the center of your screen. These hints will always be accessible until the end. If you have not been selected, this is indicated at the top of your screen.

We have also distributed a sheet of paper to each of you. If you have received hints, the sheet gives a more detailed description of these hints. If you have not received hints, the sheet has only an empty frame that you can complete.

Please do not press Continue until you have received your sheet of paper. Take time to look at this sheet. Then press Continue to see the new rules for this part.

3 minutes

A new part is about to start with different rules. In this part you will participate in the same game for another 5 periods, but in this part you will be paired with a partner. You will keep the same partner for the 5 periods.

If you received hints, your partner did not receive them and conversely, if you did not receive hints, your partner received them. At the bottom of the screen, you can see information about your performance and that of your partner in the first part.

Please press Continue.

In each period, you and your partner will have to solve the same puzzle individually, but you have the choice on how to participate in this part with your partner. You have to choose one of the following two options that will apply to the 5 periods. The differences between the options are highlighted in red on your screen.

Option 1 appears in the box on the left of your screen.

\section{With option 1:}


- You will earn $€ 1.25$ for each puzzle solved by yourself.

- At the end of each period, you will receive the same feedback as before but you will also see information about your partner's puzzle and results and vice versa.

Option 2 appears in the box on the right of your screen.

\section{With option 2:}

- You will earn $€ 1.25$ for each puzzle solved by yourself.

- At the end of each period, you will receive the same feedback as before but you will also see information about your partner's puzzle and results and vice versa.

- Your partner and you will have the opportunity to communicate after each round.

Note that the difference between these options is that you will be able to communicate with your partner in option 2, but not in option 1. Any interaction is done on the results screen only, and not while you are trying to solve the puzzle.

Please press Continue to see how the interface changes depending on the option.

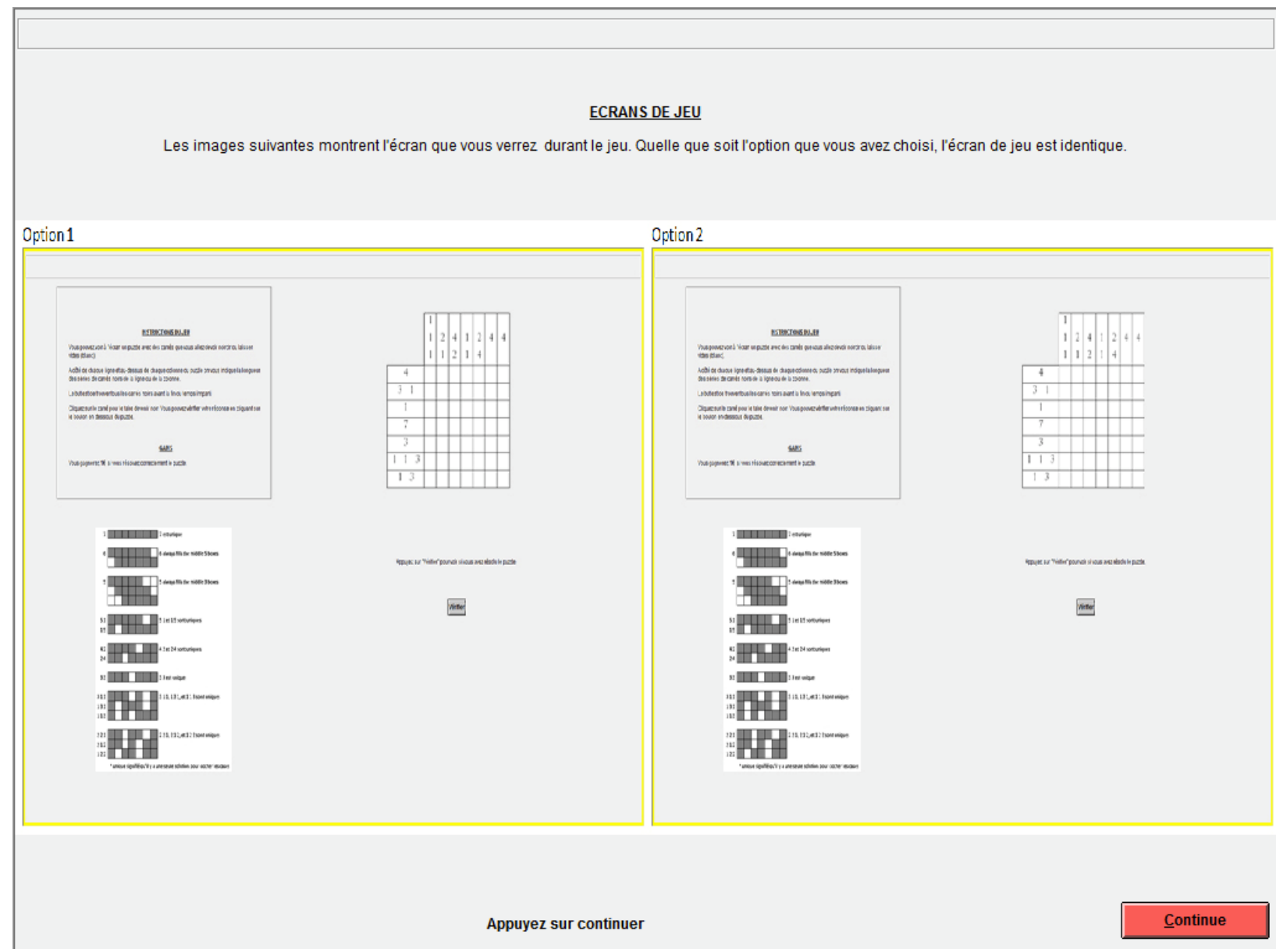

The figures show a side-by-side comparison of the screens for both options. Whichever option you have chosen, the screen is identical and it is identical to previous periods. You and your partner have to solve the 
puzzle individually. If you have been selected to receive hints, you will have access to them at the bottom left of your screen.

Please press Continue.

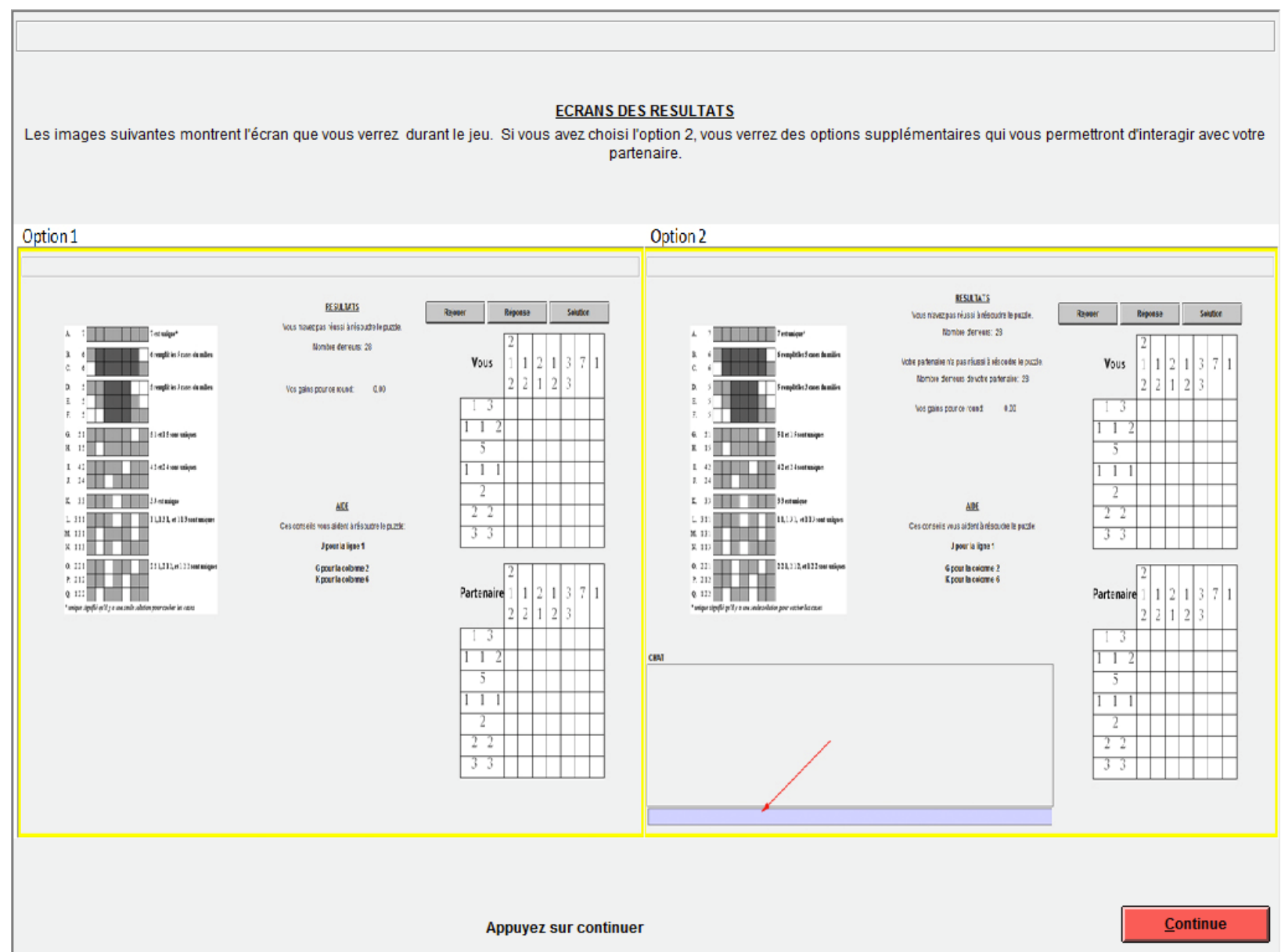

You should now see a side-by-side comparison of the results screens for both options.

In each option, you will receive information about your partner's puzzle in the middle of the screen, below your own results.

The main differences between option 1 and option 2 have been highlighted with red arrows. For option 1 , the results screen is the same as in the previous part. For option 2, the screen allows you to interact with your partner.

- First, you will also have access to your partner's grid on the right. So, when you choose Replay or Solution or Answer, it will update with your answer at the top and your partner's answer at the bottom. This is also valid for your partner who will also have access to your results.

- Second, you can freely exchange messages with your partner by writing inside the chat box at the bottom of your screen.

You can use the chat box to talk about what you want, including the information on the hints if you received them. The only restriction is that you must not try to identify yourself or use offensive language. 
Please press Continue.

You are informed that in the third and last part, you will remain matched with the same partner as in this second part. But while in this second part you have the choice of the mode of participation with your partner, in the last part:

- you will not have the choice of the option

- you and your partner will no longer have the opportunity to interact

- and $€ 1.25$ will be paid for the sum of the puzzles solved by your partner and by you. This group income will then be divided in two equal parts between you and your partner.

Please press Continue.

[ NI treatment (revenue sharing, no interactions, hints and same partner in the last part)]

PART 2

You have now completed Part 1. Please press Continue.

Before you start the second part, you should know that participants in the session ranked in the top half in terms of the number of solved puzzles (i.e., those who solved more puzzles than the median) have been selected to receive hints.

If you have been selected, you should now see the hints displayed in the center of your screen. These hints will always be accessible until the end. If you have not been selected, this is indicated at the top of your screen.

We have also distributed a sheet of paper to each of you. If you have received hints, the sheet gives a more detailed description of these hints. If you have not received hints, the sheet has only an empty frame that you can complete.

Please do not press Continue until you have received your sheet of paper. Take time to look at this sheet. Then press Continue to see the new rules for this part.

3 minutes

A new part is about to start with different rules. In this part you will participate in the same game for another 5 periods, but in this part you will be paired with a partner. You will keep the same partner for the 5 periods.

If you received hints, your partner did not receive them and conversely, if you did not receive hints, your partner received them. At the bottom of the screen, you can see information about your performance and that of your partner in the first part.

Please press Continue. 
In each period, you and your partner will have to solve the same puzzle individually, but you have the choice on how to participate in this part with your partner. You have to choose one of the following two options that will apply to the 5 periods. The differences between the options are highlighted in red on your screen.

Option 1 appears in the box on the left of your screen.

\section{With option 1:}

- You will earn $€ 1.25$ for each puzzle solved by yourself.

- At the end of each period, you will receive the same feedback as before but you will also see information about your partner's puzzle and results and vice versa.

Option 2 appears in the box on the right of your screen.

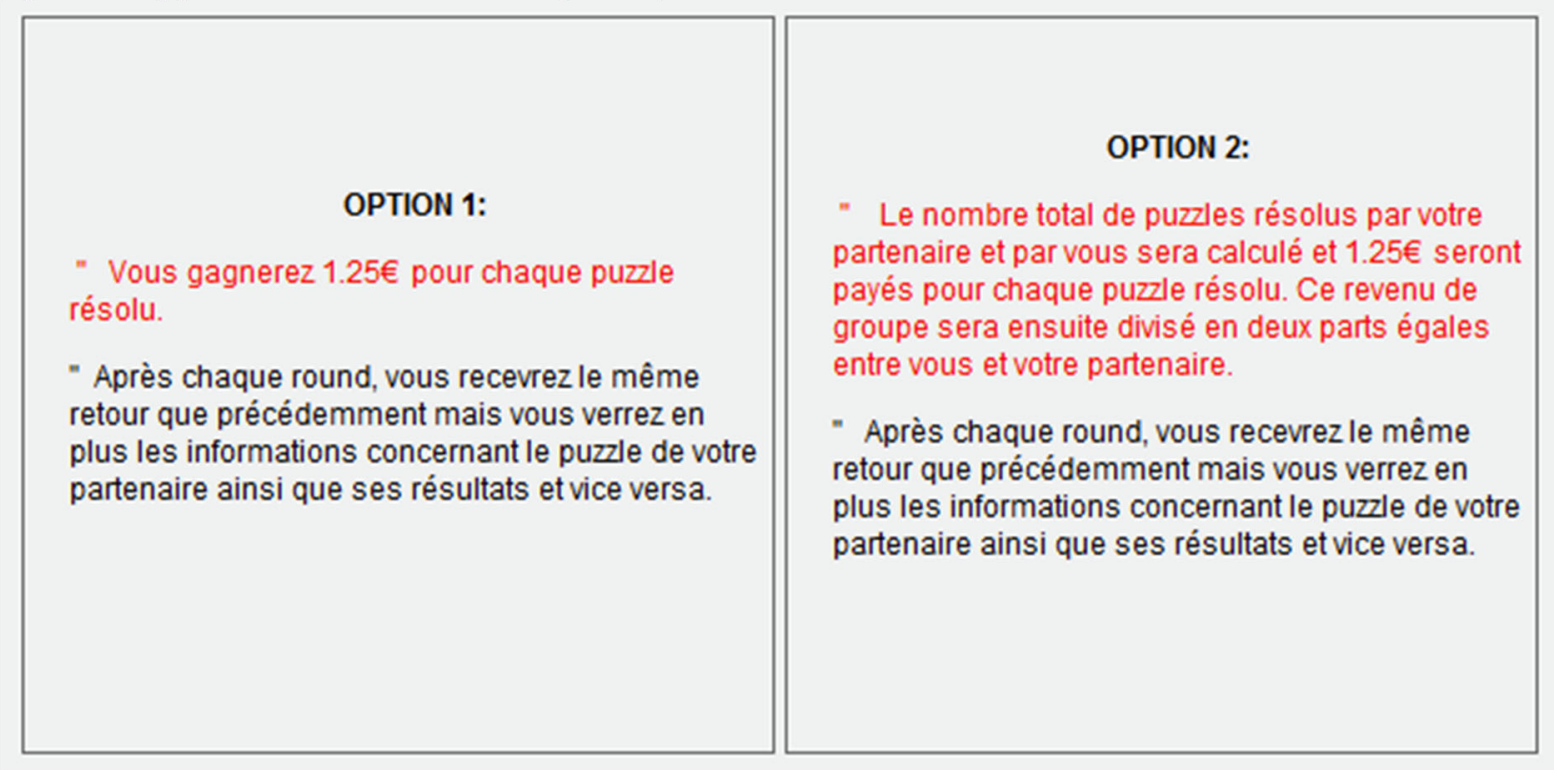

\section{With option 2:}

- The total number of puzzles solved by your partner and by you will be calculated and $€ 1.25$ will be paid for each puzzle solved. This group income will then be divided in two equal parts between you and your partner.

- After each round, you will receive the same feedback as before but you will also see information about your partner's puzzle and results and vice versa.

Note that the difference between these options is that you will share your earnings with your partner in option 2, but not in option 1.

Please press Continue to see how the interface changes depending on the option. 


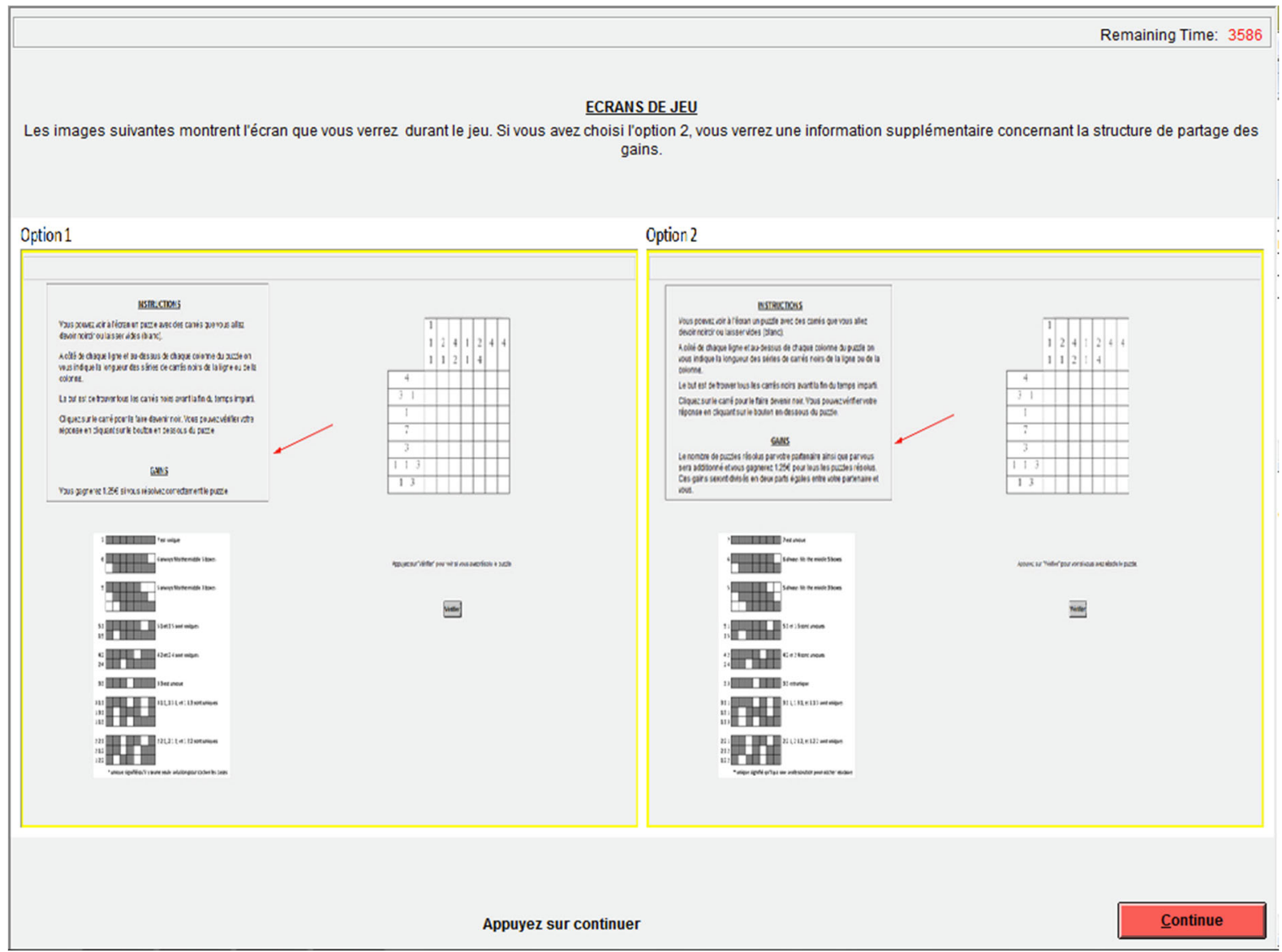

The figures show a side-by-side comparison of the screens for both options. Whichever option you have chosen, the screen is identical and it is identical to previous periods. The red arrows point to the difference in the earnings but everything else is similar. You and your partner must solve the puzzle individually. If you have been selected to receive hints, you will have access to them at the bottom left of your screen.

Please press Continue. 


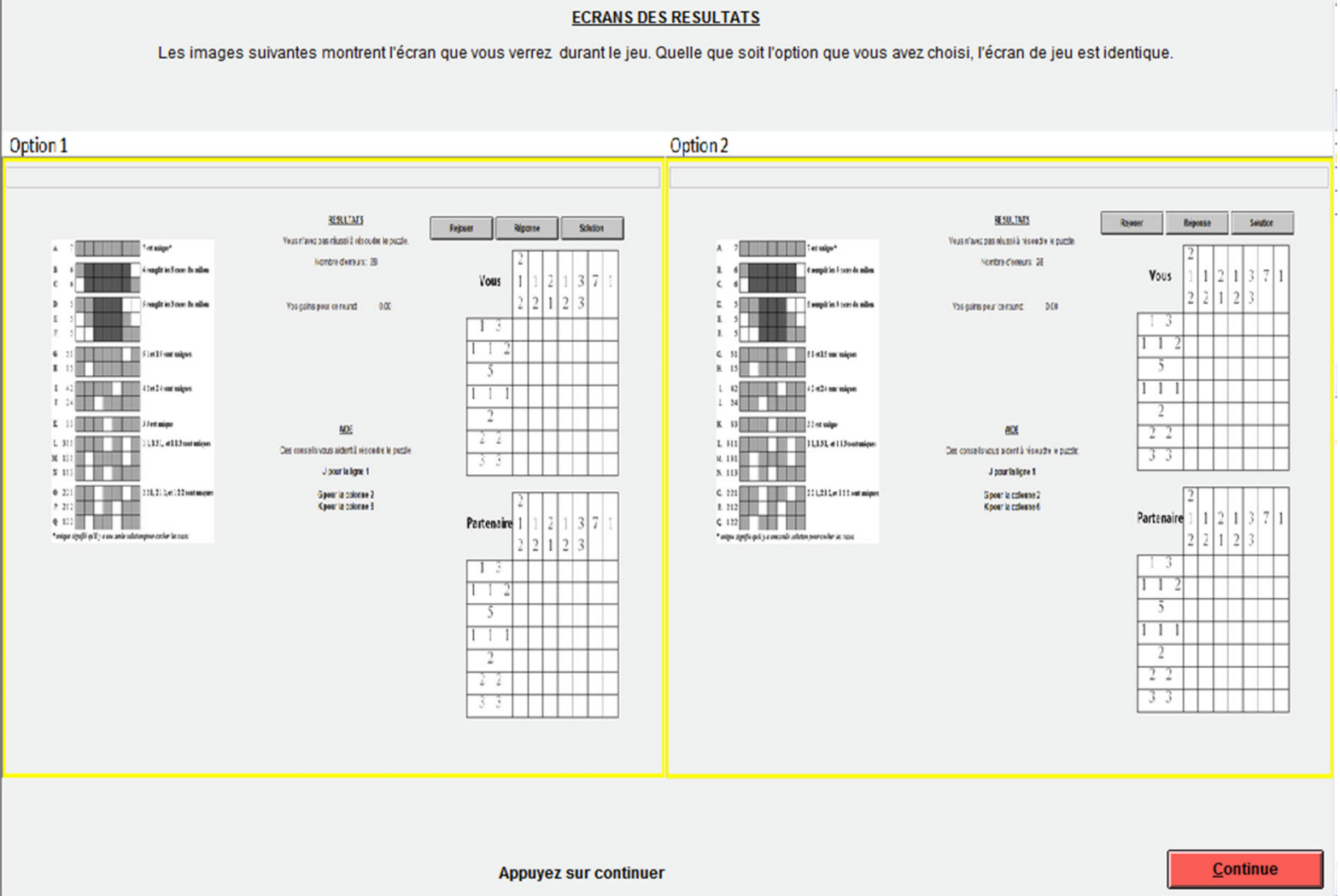

You should now see a side-by-side comparison of the results screens for both options.

In each option, you will receive information about your partner's puzzle in the middle of the screen, below your own results.

You will also have access to your partner's grid on the right. So, when you choose Replay or Solution or Answer, it will update with your answer at the top and your partner's answer at the bottom. This is also valid for your partner who will also have access to your results.

Please press Continue.

You are informed that in the third and last part, you will remain matched with the same partner as in this second part. But while in this second part you have the choice of the mode of participation with your partner, in the last part:

- you will not have the choice of the option

- and $€ 1.25$ will be paid for the sum of the puzzles solved by your partner and by you. This group income will then be divided in two equal parts between you and your partner.

Please press Continue. 
[NP treatment (revenue sharing, interactions, hints and new partner in the last part)]

\section{PART 2}

You have now completed Part 1. Please press Continue.

Before you start the second part, you should know that participants in the session ranked in the top half in terms of the number of solved puzzles (i.e., those who solved more puzzles than the median) have been selected to receive hints.

If you have been selected, you should now see the hints displayed in the center of your screen. These hints will always be accessible until the end. If you have not been selected, this is indicated at the top of your screen.

We have also distributed a sheet of paper to each of you. If you have received hints, the sheet gives a more detailed description of these hints. If you have not received hints, the sheet has only an empty frame that you can complete.

Please do not press Continue until you have received your sheet of paper. Take time to look at this sheet. Then press Continue to see the new rules for this part.

3 minutes

A new part is about to start with different rules. In this part you will participate in the same game for another 5 periods, but in this part you will be paired with a partner. You will keep the same partner for the 5 periods.

If you received hints, your partner did not receive them and conversely, if you did not receive hints, your partner received them. At the bottom of the screen, you can see information about your performance and that of your partner in the first part.

Please press Continue.

In each period, you and your partner will have to solve the same puzzle individually, but you have the choice on how to participate in this part with your partner. You have to choose one of the following two options that will apply to the 5 periods. The differences between the options are highlighted in red on your screen.

Option 1 appears in the box on the left of your screen.

\section{With option 1:}

- You will earn $€ 1.25$ for each puzzle solved by yourself.

- At the end of each period, you will receive the same feedback as before but you will also see information about your partner's puzzle and results and vice versa.

Option 2 appears in the box on the right of your screen. 


\section{OPTION 1:}

" Vous gagnerez $1.25 €$ pour chaque puzzle résolu.

" Après chaque round, vous recevrez le même retour que précédemment mais vous verrez en plus les informations concernant le puzzle de votre partenaire ainsi que ses résultats et vice versa.

\section{OPTION 2:}

" Le nombre total de puzzles résolus par votre partenaire et par vous sera calculé et $1.25 €$ seront payés pour chaque puzzle résolu. Ce revenu de groupe sera ensuite divisé en deux parts égales entre vous et votre partenaire.

" Après chaque round, vous recevrez le même feedback que précédemment mais vous verrez en plus les informations concernant le puzzle de votre partenaire ainsi que ses résultats et vice versa (votre partenaire verra les informations sur votre puzzle et vos résultats).

" Votre partenaire et vous aurez l'opportunité de communiquer après chaque round.

\section{With option 2:}

- The total number of puzzles solved by your partner and by you will be calculated and $€ 1.25$ will be paid for each puzzle solved. This group income will then be divided in two equal parts between you and your partner.

- After each round, you will receive the same feedback as before but you will also see information about your partner's puzzle and results and vice versa.

- Your partner and you will have the opportunity to communicate after each round.

Note that the difference between these options is that you will be able to communicate with your partner and you will share your earnings with your partner in option 2, but not in option 1. Any interaction is done on the results screen only, and not while you are trying to solve the puzzle.

Please press Continue to see how the interface changes depending on the option. 
ECRANS DE JEU

Les images suivantes montrent l'écran que vous verrez durant le jeu. Si vous avez choisi l'option 2 , vous verrez une information supplémentaire concernant la structure de partage des gains.

Option 1

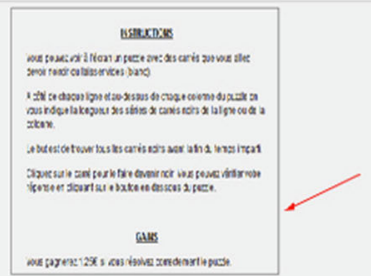

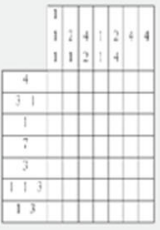

Option 2
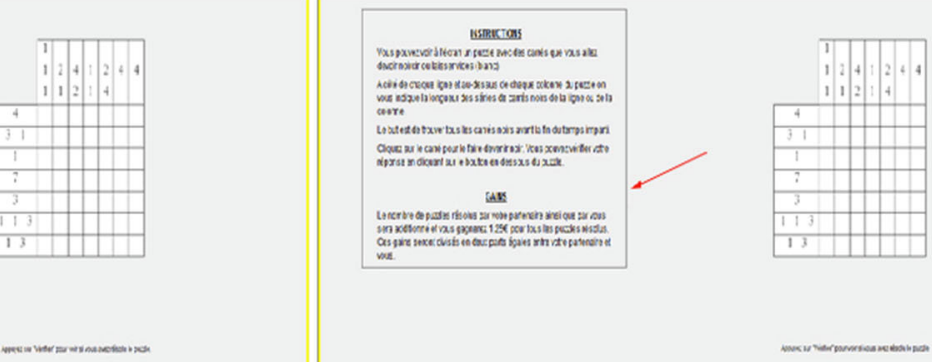

回

The figures show a side-by-side comparison of the screens for both options. Whichever option you have chosen, the screen is identical and it is identical to previous periods. The red arrows point to the difference in the earnings but everything else is similar. You and your partner must solve the puzzle individually. If you have been selected to receive hints, you will have access to them at the bottom left of your screen.

Please press Continue. 


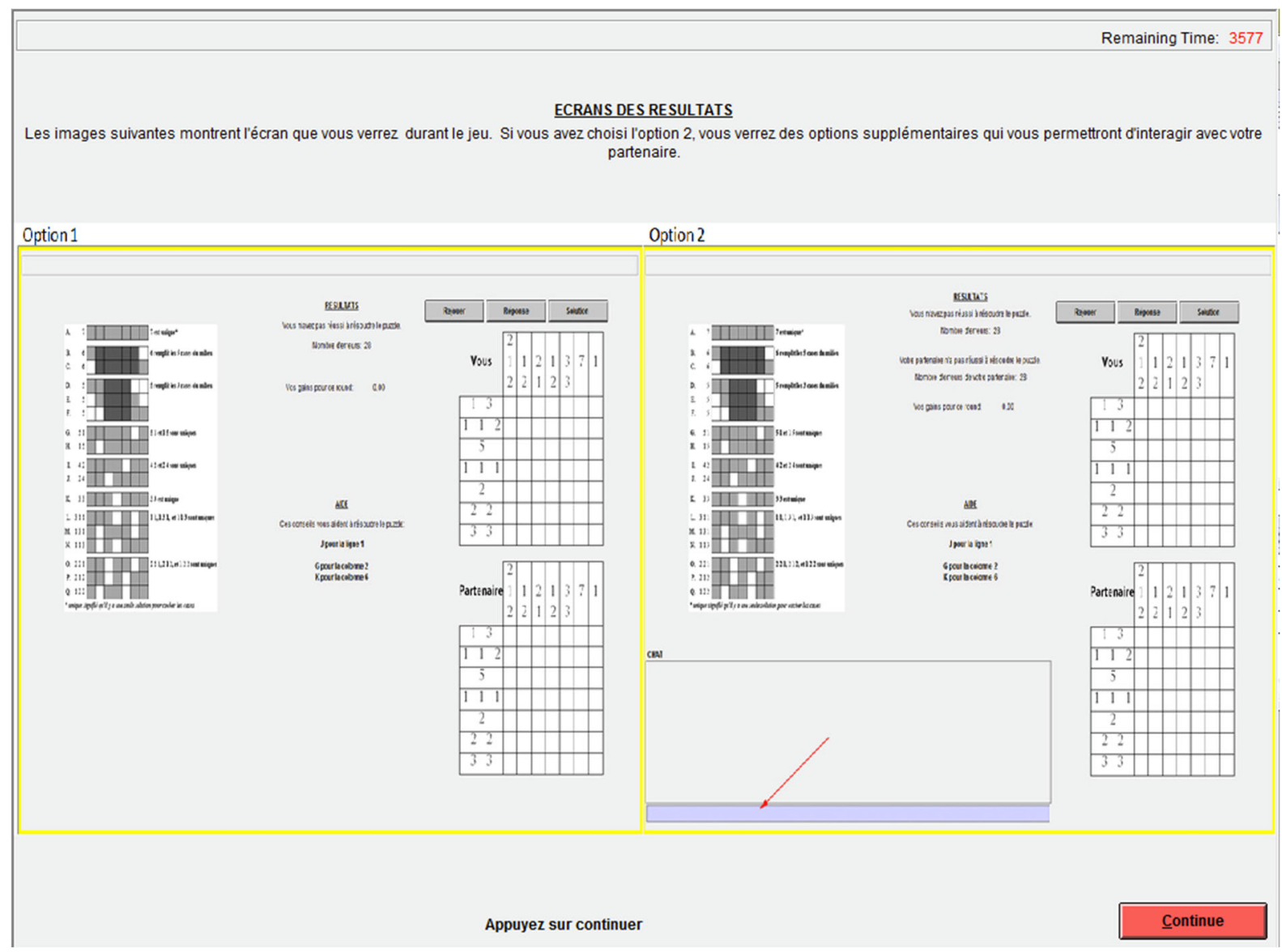

You should now see a side-by-side comparison of the results screens for both options.

In each option, you will receive information about your partner's puzzle in the middle of the screen, below your own results.

The main differences between option 1 and option 2 have been highlighted with red arrows. For option 1 , the results screen is the same as in the previous part. For option 2, the screen allows you to interact with your partner.

- First, you will also have access to your partner's grid on the right. So, when you choose Replay or Solution or Answer, it will update with your answer at the top and your partner's answer at the bottom. This is also valid for your partner who will also have access to your results.

- Second, you can freely exchange messages with your partner by writing inside the chat box at the bottom of your screen.

You can use the chat box to talk about what you want, including the information on the hints if you received them. The only restriction is that you must not try to identify yourself or use offensive language.

\section{Please press Continue.}

You are informed that in the third and last part, you will be matched with a new partner, different from your partner in this second part. If you have received hints, this new partner will not have received them, and conversely, if you have not received hints, this new partner will have received them. 
Moreover, while in this second part you have the choice of the mode of participation with your partner, in the last part:

- you will not have the choice of the option

- you and your partner will not have the opportunity to interact

- and $€ 1.25$ will be paid for the sum of the puzzles solved by your partner and by you. This group income will then be divided in two equal parts between you and your partner.

Please press Continue.

[NH treatment (revenue sharing, interactions, no hints and same partner in the last part)]

\section{PART 2}

You have now completed Part 1. Please press Continue.

A new part is about to start with different rules. In this part you will participate in the same game for another 5 periods, but in this part you will be paired with a partner. You will keep the same partner for the 5 periods.

Before you start the second part, you should know that participants in the session have been ranked in the top half in terms of the number of solved puzzles (i.e., those who solved more puzzles than the median) or not.

Your screen will indicate whether you have been ranked in the top half of all participants in terms of the number of solved puzzles.

If you have been ranked in the top half, your partner has not been, and conversely, if you have not been ranked in the top half, your partner has been. At the bottom of the screen, you can see information about your performance and that of your partner in the first part.

Please press Continue.

In each period, you and your partner will have to solve the same puzzle individually, but you have the choice on how to participate in this part with your partner. You have to choose one of the following two options that will apply to the 5 periods. The differences between the options are highlighted in red on your screen.

Option 1 appears in the box on the left of your screen.

\section{With option 1:}

- You will earn $€ 1.25$ for each puzzle solved by yourself.

- At the end of each period, you will receive the same feedback as before but you will also see information about your partner's puzzle and results and vice versa.

Option 2 appears in the box on the right of your screen. 


\section{OPTION 1:}

" Vous gagnerez $1.25 €$ pour chaque puzzle résolu.

" Après chaque round, vous recevrez le même retour que précédemment mais vous verrez en plus les informations concernant le puzzle de votre partenaire ainsi que ses résultats et vice versa.

\section{OPTION 2:}

" Le nombre total de puzzles résolus par votre partenaire et par vous sera calculé et $1.25 €$ seront payés pour chaque puzzle résolu. Ce revenu de groupe sera ensuite divisé en deux parts égales entre vous et votre partenaire.

" Après chaque round, vous recevrez le même feedback que précédemment mais vous verrez en plus les informations concernant le puzzle de votre partenaire ainsi que ses résultats et vice versa (votre partenaire verra les informations sur votre puzzle et vos résultats).

" Votre partenaire et vous aurez l'opportunité de communiquer après chaque round.

\section{With option 2:}

- The total number of puzzles solved by your partner and by you will be calculated and $€ 1.25$ will be paid for each puzzle solved. This group income will then be divided in two equal parts between you and your partner.

- After each round, you will receive the same feedback as before but you will also see information about your partner's puzzle and results and vice versa.

- Your partner and you will have the opportunity to communicate after each round.

Note that the difference between these options is that you will be able to communicate with your partner and you will share your earnings with your partner in option 2, but not in option 1. Any interaction is done on the results screen only, and not while you are trying to solve the puzzle.

Please press Continue to see how the interface changes depending on the option. 
ECRANS DE JEU

Les images suivantes montrent l'écran que vous verrez durant le jeu. Si vous avez choisi l'option 2 , vous verrez une information supplémentaire concernant la structure de partage des gains.

Option1

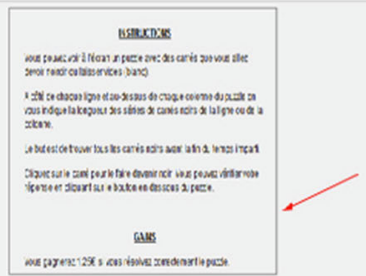

Option 2
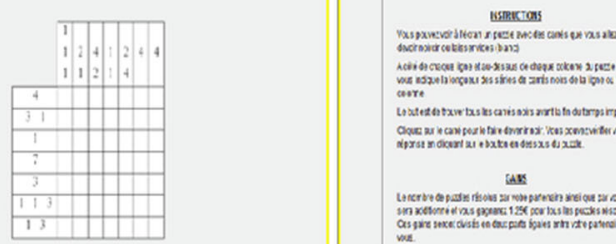

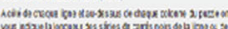
corr.

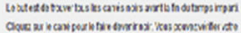

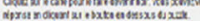

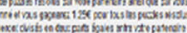
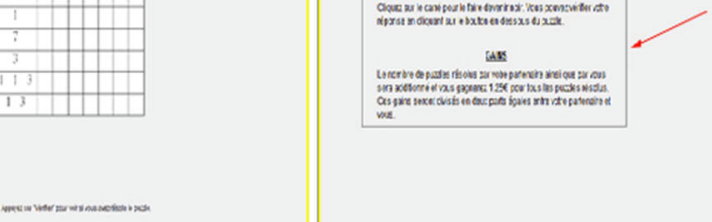

$\square$

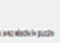

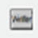

The figures show a side-by-side comparison of the screens for both options. Whichever option you have chosen, the screen is identical and it is identical to previous periods. The red arrows point to the difference in the earnings but everything else is similar. You and your partner must solve the puzzle individually.

Please press Continue. 


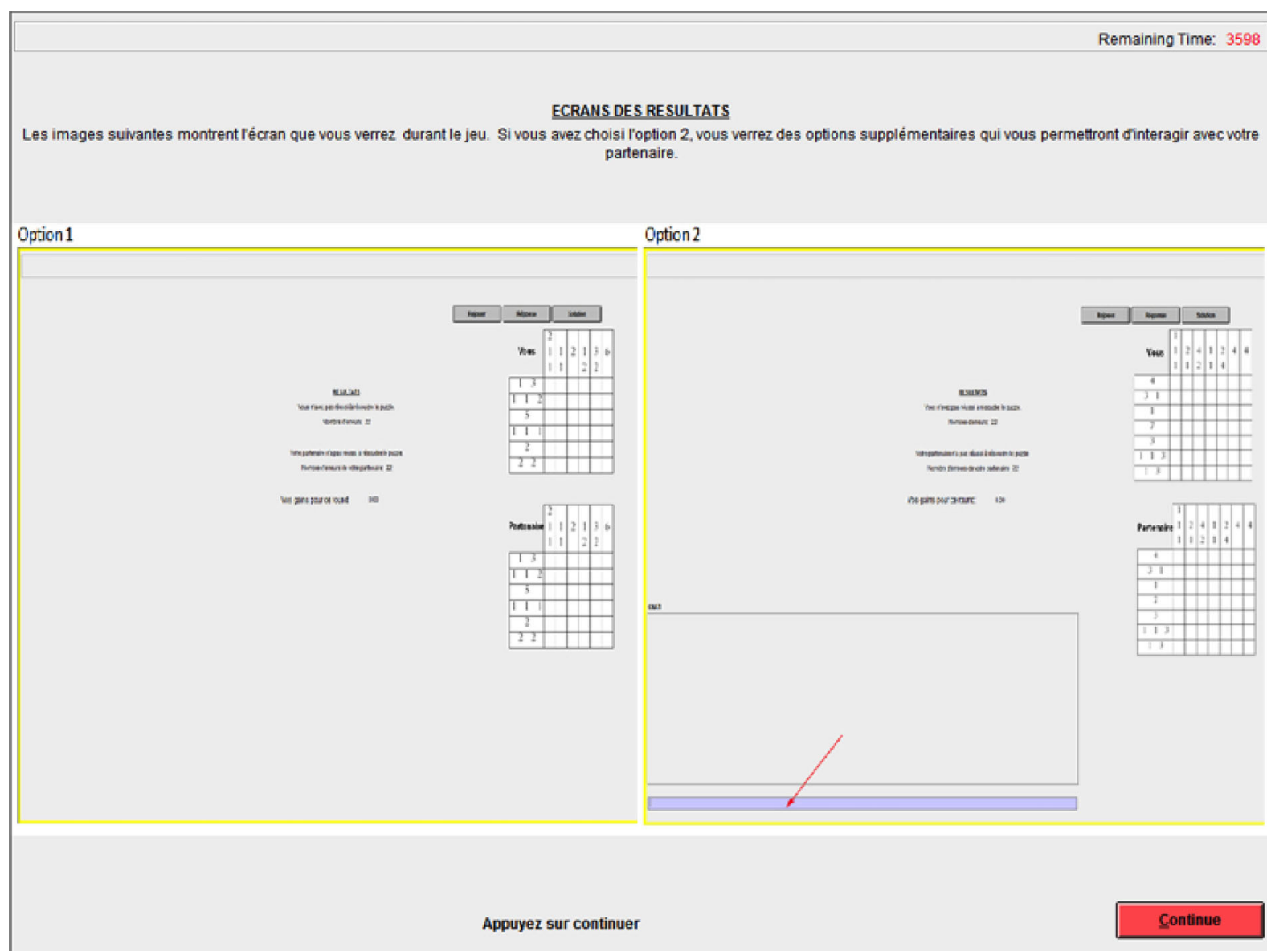

You should now see a side-by-side comparison of the results screens for both options.

In each option, you will receive information about your partner's puzzle in the middle of the screen, below your own results.

The main differences between option 1 and option 2 have been highlighted with red arrows. For option 1 , the results screen is the same as in the previous part. For option 2, the screen allows you to interact with your partner.

- First, you will also have access to your partner's grid on the right. So, when you choose Replay or Solution or Answer, it will update with your answer at the top and your partner's answer at the bottom. This is also valid for your partner who will also have access to your results.

- Second, you can freely exchange messages with your partner by writing inside the chat box at the bottom of your screen.

You can use the chat box to talk about what you want. The only restriction is that you must not try to identify yourself or use offensive language.

Please press Continue.

You are informed that in the third and last part, you will remain matched with the same partner as in this second part. But while in this second part you have the choice of the mode of participation with your partner, in the last part: 
- you will not have the choice of the option

- you and your partner will no longer have the opportunity to interact

- and $€ 1.25$ will be paid for the sum of the puzzles solved by your partner and by you. This group income will then be divided in two equal parts between you and your partner.

Please press Continue.

\section{[ All treatments]}

In this current part 2, you will also receive a fixed payment that will be added to your other earnings. This fixed payment was randomly generated for each option. It is between 0 and 100 Euro cents. Each amount in this interval is as likely to be selected. These amounts are probably different depending on the option and across participants.

You can see the amount of the fixed payment at the bottom of each option, written in blue and italics.

If you and your partner make the same choice of option (option 1 or option 2), this choice will apply throughout this part. If you make a different choice, the option that will apply to you and your partner will be determined by a random draw in which each option has the same chance of being selected. But in any case, the fixed payment you will earn is that of the option you have chosen.

Now please select your preferred option for this part, either option 1 or option 2.

On your screen, you can now see a summary of your choice and your fixed payment for that part.

Please note that if you did not receive the option of your choice, it is because you and your partner did not make the same choice and one of the two options was randomly drawn.

Please press Continue to start the first period.

[ All treatments except NP treatment (revenue sharing, interactions, hints and new partner in the last part)]

\section{PART 3}

You have now completed part 2. Please press Continue.

In this part you will be paired with the same partner as in part 2 and you will keep the same partner throughout part 3 .

This part consists of 590 -second periods of the game. The total number of puzzles solved by your partner and by you will be calculated and $€ 1.25$ will be paid for each puzzle solved. This group income will then be divided in two equal parts between you and your partner.

At the end of this section, several questionnaires will appear on your screen. 
Please press Continue to start the first period.

[ NP treatment (revenue sharing, interactions, hints and new partner in the last part)]

\section{PART 3}

You have now completed part 2. Please press Continue.

In this part you will be paired with a new partner, different from your partner in part 2. If you received hints, this new partner did not receive them, and conversely, if you did not receive hints, this new partner received them. You will keep the same partner throughout part 3.

This part consists of 590 -second periods of the game. The total number of puzzles solved by your partner and by you will be calculated and $€ 1.25$ will be paid for each puzzle solved. This group income will then be divided in two equal parts between you and your partner.

At the end of this section, several questionnaires will appear on your screen.

Please press Continue to start the first period. 


\section{ONLINE APPENDIX 2: HINTS AND THE ICE BREAKER ACTIVITY}

Figure A1. Hints

\section{High Ability Types}
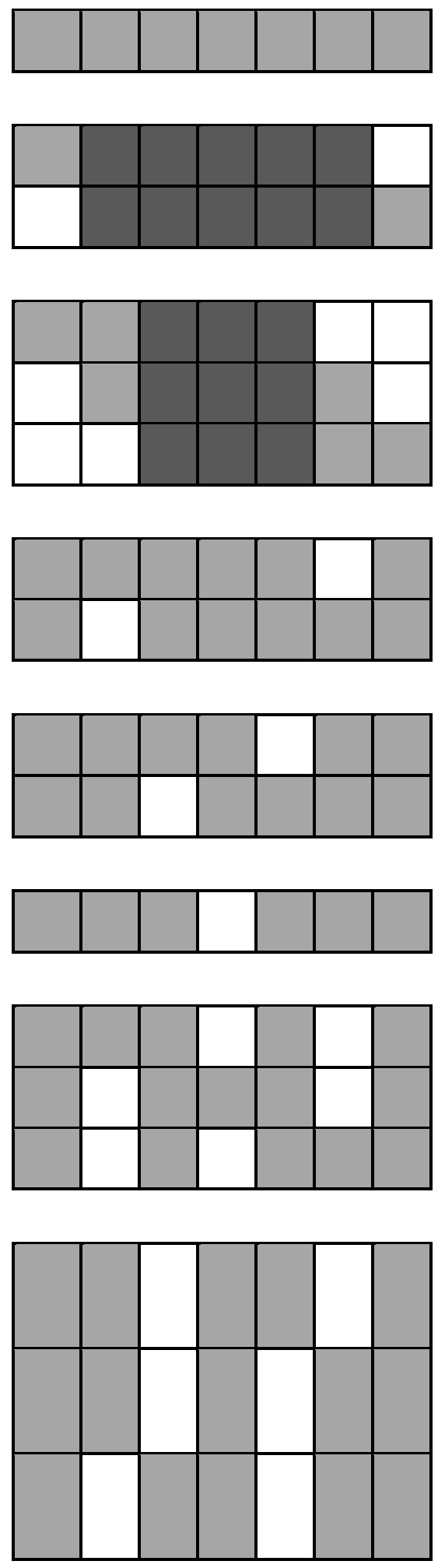

With 7, fill all boxes.

With 6 , fill the 5 boxes in the middle. The sixth box is either on the left or the right.

With $\mathbf{5}$, fill the 3 boxes in the middle.

With 5 and 1, fill the first 5 boxes, leave 1 box unfilled, and fill the last box.

With 1 and 5, fill the first box, leave 1 box unfilled, and fill the last 5 boxes.

With 4 and 2, fill the first 4 boxes, leave 1 box unfilled, and fill the last 2 boxes.

With 2 and 4, fill the first 2 boxes, leave 1 box unfilled, and fill the last 4 boxes.

With 3 and 3, fill the first 3 boxes, leave 1 box unfilled, and fill the last 3 boxes.

With 3, 1 and 1, fill the first 3 boxes, leave 1 box unfilled, fill 1 box, leave 1 box unfilled, and fi

With 1, 3 and 1, fill the first box, leave 1 box unfilled, fill 3 boxes, leave 1 box unfilled, and fi With 1, 1 and 3, fill the first box, leave 1 box unfilled, fill 1 box, leave 1 box unfilled, and fill th

With 2, 2 and 1, fill the first 2 boxes, leave 1 box unfilled, fill 2 boxes, leave 1 box unfilled, a box.

With 2, 1 and 2, fill the first 2 boxes, leave 1 box unfilled, fill 1 box, leave 1 box unfilled, an boxes.

With 1, 2 and 2, fill the first box, leave 1 box unfilled, fill 2 boxes, leave 1 box unfilled, and boxes. 


\section{Low Ability Types}
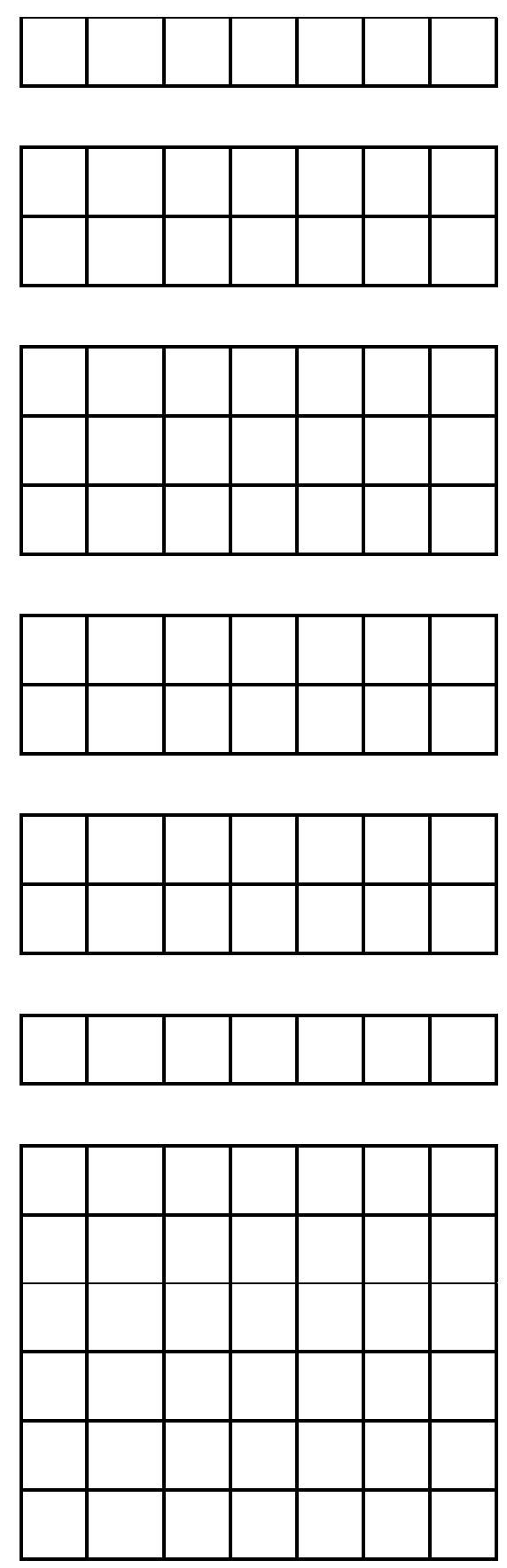


\section{Figure A2. Ice Breaker - Versions 1 and 2}

$\underline{\text { Version 1, Autograph }}$

Your objective is to complete a row or a column or a diagonal of 4 boxes with the signatures of other participants in today's session that correspond to the characteristics described by these boxes. A person can sign only one box and you cannot sign your own sheet.

\begin{tabular}{|c|c|c|c|}
\hline $\begin{array}{c}\text { Has hands bigger than } \\
\text { yours }\end{array}$ & Has two sisters & $\begin{array}{l}\text { Knows who was the } \\
\text { President of the French } \\
\text { Republic in } 1973\end{array}$ & $\begin{array}{l}\text { Went on holiday in } \\
\text { Europe (outside } \\
\text { France) this summer }\end{array}$ \\
\hline Has a cat & $\begin{array}{l}\text { Knows what the } \\
\text { acronym GATE stands } \\
\text { for }\end{array}$ & $\begin{array}{c}\text { Has the same eye color } \\
\text { as you }\end{array}$ & $\begin{array}{c}\text { Has worked as a baby } \\
\text { sitter }\end{array}$ \\
\hline $\begin{array}{l}\text { Knows how to play } \\
\text { piano }\end{array}$ & $\begin{array}{l}\text { Has the same favorite } \\
\text { bar in Lyon as you }\end{array}$ & $\begin{array}{l}\text { Has driven a } \\
\text { motorcycle }\end{array}$ & $\begin{array}{l}\text { Has a mother with the } \\
\text { same name as yours }\end{array}$ \\
\hline Born in the Paris region & $\begin{array}{c}\text { Can rub their belly and } \\
\text { tap their head at the } \\
\text { same time }\end{array}$ & Met someone famous & Is taller than $1 \mathrm{~m} 83$ \\
\hline
\end{tabular}


Version 2, Autograph

Your objective is to complete a row or a column or a diagonal of 4 boxes with the signatures of other participants in today's session that correspond to the characteristics described by these boxes. A person can sign only one box and you cannot sign your own sheet.

\begin{tabular}{|c|c|c|c|}
\hline $\begin{array}{l}\text { Can draw a } 6 \text { in the air } \\
\text { with one finger and } \\
\text { draw an } 8 \text { at the same } \\
\text { time on the ground with } \\
\text { one foot }\end{array}$ & $\begin{array}{l}\text { Born outside the } \\
\text { Rhône-Alpes region }\end{array}$ & Shorter than $1 \mathrm{~m} 83$ & Has two brothers \\
\hline Has gone scuba diving & $\begin{array}{l}\text { Knows what the } \\
\text { acronym GATE stands } \\
\text { for }\end{array}$ & $\begin{array}{c}\text { Has the same favorite } \\
\text { restaurant in Lyon as } \\
\text { you }\end{array}$ & $\begin{array}{l}\text { Knows how to play } \\
\text { guitar }\end{array}$ \\
\hline $\begin{array}{l}\text { Worked in a store this } \\
\text { summer }\end{array}$ & $\begin{array}{c}\text { Has the same hair color } \\
\text { as you }\end{array}$ & $\begin{array}{l}\text { Has smaller hands than } \\
\text { yours }\end{array}$ & $\begin{array}{l}\text { Has a father with the } \\
\text { same name as yours }\end{array}$ \\
\hline $\begin{array}{l}\text { Went on holiday } \\
\text { outside Europe this } \\
\text { summer }\end{array}$ & $\begin{array}{l}\text { Knows who was the } \\
\text { President of the French } \\
\text { Republic in } 1975\end{array}$ & Met someone famous & Has a dog \\
\hline
\end{tabular}




\section{ONLINE APPENDIX 3: EXTENDING THE MODEL TO \\ INCLUDE COMPLEMENTARITIES}

The purpose of this appendix is to extend the model presented in Section 4 to allow for direct complementarities in production. Our focus is solely on decisions by high ability types, but the model extends in a natural fashion to cover decisions by low ability types. We make two major modifications to the model: (1) The profit functions are modified to incorporate complementarities. Let profits for a high ability type working alone in Stage t equal $(1-k) S_{H}^{t}$, where $0 \leq \mathrm{k} \leq 1 .{ }^{30}$ For a high ability type working in a team, profits become $(1-k) p\left(\frac{1}{2} S_{H}^{t}+\frac{1}{2} S_{L}^{t}(\tau)\right)+k p\left(S_{H}^{t} \times S_{L}^{t}(\tau)\right)$. If $\mathrm{k}=0$, this is the original model with no complementarities. If $\mathrm{k}=1$, subjects can only make a profit by joining a team. Intuitively, complementarities are sufficiently high that production only occurs with inputs from both members of a team. (2) We previously treated $\tau$ as a binary variable, but we now define it as a continuous variable where $0 \leq \tau \leq 1$. We assume $\tau=0$ if no interaction (and hence no teaching) takes place. If interaction occurs, $\tau>$ 0 . Varying $\tau$ captures differences in how much teaching occurs with interaction. Making $\tau$ a continuous variable lets us calculate marginal effects of increased teaching. $S_{L}^{t}(\tau)$ and $\theta_{H}^{2}(\tau)$ are assumed to be strictly increasing functions of $\tau$. We assume that $S_{L}^{t}(\tau)$ and $S_{H}^{t}$ are uncorrelated for all $\tau \geq 0$, implying that $E\left(S_{L}^{t}(\tau) \times S_{H}^{t}\right)=E S_{L}^{t}(\tau) \times E S_{H}^{t}$

We start with the NI treatment where neither teaching nor social interactions take place. In the original model without complementarities, Option 2 is chosen if the following inequality holds. This is (2) in the main text, but modified for a high ability type.

$$
(\alpha-0.5) p\left(E S_{L}^{2}(0)-E S_{H}^{2}\right)+\varepsilon>0(\mathbf{A 1})
$$

With the modification of the model to allow for complementarities, (A1) is transformed into (A2). The term on the left gives a high ability type's gains from joining a team due to complementarities, and the right

\footnotetext{
${ }^{30}$ The model assumes that the productivity of high ability types does not depend on whether or not they engage in teaching, so we have simplified the notation by suppressing that $S_{H}^{t}$ is a function of teaching.
} 
hand side gives their losses from having to revenue share with a low ability type. Unlike the original model, it is now possible that high ability types will want to join a team independent of the Heckman draws. Nevertheless, $\mathbf{H} 1$ still holds since the term on the left side is positive for high ability types and negative for low ability types.

$$
k p\left(E S_{H}^{2} \times E S_{L}^{2}(0)\right)+\varepsilon>(1-k)(\alpha-0.5) p\left(E S_{H}^{2}-E S_{L}^{2}(0)\right)
$$

Turning to the BL treatment, the benefits of Option 2 for high ability now include gains from increased productivity of the low ability type due to teaching, non-pecuniary benefits of teaching, and non-pecuniary benefits from social interaction. Reflecting complementarities, (3) in the main text is modified into (A3).

$$
\begin{gathered}
k p\left(E S_{H}^{2} \times E S_{L}^{2}(0)\right)+p\left(\frac{(1-k)}{2}+k E S_{H}^{2}\right)\left(E S_{L}^{2}(\tau)-E S_{L}^{2}(0)\right)+p\left(\frac{(1-k)}{2}+k E S_{H}^{3}\right)\left(E S_{L}^{3}(\tau)-E S_{L}^{3}(0)\right) \\
+\theta_{H}^{2}(\tau)+\mu_{H}^{2}+\varepsilon>(1-k)(\alpha-0.5) p\left(E S_{H}^{2}-E S_{L}^{2}(0)\right)(\mathbf{A 3})
\end{gathered}
$$

While more complicated, the intuition underlying (A3) mirrors that of (3) in the main text. The second and third terms on the left side are monetary gains from teaching the low ability type. The fourth and fifth terms are non-pecuniary benefits of teaching and utility from social interaction. Since all these terms are positive, H2 still holds. The logic underlying H3 - H6 is unchanged from the original model, so all of these hypotheses hold as well. Adding direct complementarities to production would not change our predictions about how the various treatments would affect the willingness of high ability types to join teams.

Several additional points can be taken away from this simple modeling exercise. First, if we make the fairly weak assumptions that $E S_{H}^{2}>1 / 2$ and $E S_{H}^{3}>1 / 2$, the probability of a high ability type choosing a team is an increasing function of either $k$ or $\tau$. Second, the interaction between complementarities $(k)$ and teaching $(\tau)$ implies that the effects of $k$ and $\tau$ are not separable; the marginal effect of $k$ on the probability of choosing a team is an increasing function of $\tau$ and vice versa. Finally, we cannot state whether the marginal effect of $k$ or $\tau$ is larger, but we can note some factors that drive the relative size of the effects. Rewriting (A3) as $\Delta$ $+\varepsilon>0$, let $E=1-F(-\Delta)$ be the probability of a high ability type choosing Option 2 where $F$ is the cdf of $\varepsilon$. The derivative $\mathrm{dE} / \mathrm{dk}=\mathrm{f}(-\Delta) \times \mathrm{d} \Delta / \mathrm{dk}$. The derivative $\mathrm{d} \Delta / \mathrm{dk}$ is bounded below by the product $E S_{H}^{2} \times$ $E S_{L}^{2}(0)$. This implies, as one might expect, that the marginal effect of increasing the importance of direct 
complementarities is large. On the other hand, the magnitude of the derivative $\mathrm{d} \Delta / \mathrm{d} \tau$ is governed by the magnitude of the derivatives $\mathrm{d} S_{L}^{2}(\tau) / \mathrm{d} \tau, \mathrm{d} S_{L}^{3}(\tau) / \mathrm{d} \tau$, and $\mathrm{d} \theta_{H}^{2}(\tau) / \mathrm{d} \tau$. In other words, we cannot say how much changing $\tau$ affects the probability that a high ability type chooses to join a team without knowing the impact of teaching on the productivity of low ability types and the non-pecuniary benefits of teaching for high ability types. These are empirical questions. 
ONLINE APPENDIX 4: ANALYSIS OF THE CHOICE OF OPTION

Table A1: Probit Regressions on Choice of Option 2 (clustering version)

\begin{tabular}{|c|c|c|c|c|}
\hline & \multicolumn{2}{|c|}{ Low Ability Types } & \multicolumn{2}{|c|}{ High Ability Types } \\
\hline & Model 1L & Model 2L & Model 1H & Model 2H \\
\hline Own, Stage 1 Correct & $\begin{array}{c}-0.077 * * * \\
(0.027)\end{array}$ & $-0.083^{* * *}$ & $\begin{array}{c}-0.052 \\
(0.037)\end{array}$ & $\begin{array}{c}-0.039 \\
(0.040)\end{array}$ \\
\hline Partner, Stage 1 Correct & $\begin{array}{c}0.010 \\
(0.045)\end{array}$ & $\begin{array}{c}0.015 \\
(0.045)\end{array}$ & $\begin{array}{c}0.016 \\
(0.024)\end{array}$ & $\begin{array}{c}0.019 \\
(0.023)\end{array}$ \\
\hline Difference, Heckman Draws & $\begin{array}{c}0.052 * * * \\
(0.008)\end{array}$ & $\begin{array}{c}0.052 * * * \\
(0.008)\end{array}$ & $\begin{array}{c}0.011 \\
(0.007)\end{array}$ & $\begin{array}{c}0.012 * \\
(0.007)\end{array}$ \\
\hline PR & $\begin{array}{c}0.129 \\
(0.097)\end{array}$ & $\begin{array}{c}0.134 \\
(0.097)\end{array}$ & $\begin{array}{c}0.387 * * * \\
(0.087)\end{array}$ & $\begin{array}{c}0.394 * * * \\
(0.084)\end{array}$ \\
\hline NI & $\begin{array}{c}0.041 \\
(0.081)\end{array}$ & $\begin{array}{c}0.045 \\
(0.081) \\
\end{array}$ & $\begin{array}{c}-0.209^{* * *} \\
(0.071)\end{array}$ & $\begin{array}{r}-0.205 * * * \\
(0.070)\end{array}$ \\
\hline NP & $\begin{array}{c}0.047 \\
(0.099)\end{array}$ & $\begin{array}{c}0.054 \\
(0.096)\end{array}$ & $\begin{array}{c}-0.193^{* * *} \\
(0.072)\end{array}$ & $\begin{array}{c}-0.194 * * * \\
(0.070)\end{array}$ \\
\hline NH & $\begin{array}{c}0.015 \\
(0.086)\end{array}$ & $\begin{array}{c}0.042 \\
(0.085)\end{array}$ & $\begin{array}{c}-0.154^{*} \\
(0.083)\end{array}$ & $\begin{array}{r}-0.153^{*} \\
(0.083)\end{array}$ \\
\hline Ice Breaker & $\begin{array}{l}-0.015 \\
(0.062)\end{array}$ & $\begin{array}{c}0.003 \\
(0.063)\end{array}$ & $\begin{array}{l}-0.107^{*} \\
(0.056)\end{array}$ & $\begin{array}{l}-0.101^{*} \\
(0.056)\end{array}$ \\
\hline CRT Score & & $\begin{array}{c}0.029 \\
(0.032)\end{array}$ & & $\begin{array}{l}-0.013 \\
(0.033)\end{array}$ \\
\hline Age & & $\begin{array}{l}0.010^{*} \\
(0.005)\end{array}$ & & $\begin{array}{c}0.009 \\
(0.012)\end{array}$ \\
\hline Female & & $\begin{array}{l}-0.024 \\
(0.062) \\
\end{array}$ & & $\begin{array}{c}-0.082 \\
(0.071) \\
\end{array}$ \\
\hline Log-likelihood & -131.32 & -129.92 & -109.26 & -108.24 \\
\hline $\mathrm{AIC}$ & 280.64 & 283.85 & 236.52 & 240.47 \\
\hline $\mathrm{BIC}$ & 311.85 & 325.46 & 267.73 & 282.09 \\
\hline
\end{tabular}

Notes: All regressions are based on 237 observations. Marginal effects are reported. Standard errors corrected for clustering are reported in parentheses. Three $(* * *)$, two $(* *)$, and one $(*)$ stars indicate significance at the $1 \%, 5 \%$, and $10 \%$ level, respectively. 
Table A2: Probit Regressions on Choice of Option 2 for High Ability Types Different Corrections for Session Effects

\begin{tabular}{|c|c|c|c|c|}
\hline $\begin{array}{l}\text { S.E. Type } \\
\text { Level }\end{array}$ & $\begin{array}{c}\text { Robust } \\
\text { Individual }\end{array}$ & $\begin{array}{l}\text { Clustered } \\
\text { Mixed }\end{array}$ & $\begin{array}{l}\text { Cluster } \\
\text { Session } \\
\end{array}$ & $\begin{array}{l}\text { R.E. \& Robust } \\
\text { Session }\end{array}$ \\
\hline Own, Stage 1 Correct & $\begin{array}{l}-0.052 \\
(0.041)\end{array}$ & $\begin{array}{l}-0.052 \\
(0.037)\end{array}$ & $\begin{array}{l}-0.052 \\
(0.038)\end{array}$ & $\begin{array}{c}-0.043 \\
(0.031)\end{array}$ \\
\hline Partner, Stage 1 Correct & $\begin{array}{c}0.016 \\
(0.025)\end{array}$ & $\begin{array}{c}0.016 \\
(0.024)\end{array}$ & $\begin{array}{c}0.016 \\
(0.023)\end{array}$ & $\begin{array}{c}0.014 \\
(0.020)\end{array}$ \\
\hline Difference, Heckman Draws & $\begin{array}{c}0.011 \\
(0.007)\end{array}$ & $\begin{array}{c}0.011 \\
(0.007)\end{array}$ & $\begin{array}{c}0.011 \\
(0.008)\end{array}$ & $\begin{array}{c}0.009 \\
(0.007)\end{array}$ \\
\hline $\mathbf{P R}$ & $\begin{array}{c}0.387 * * * \\
(0.097)\end{array}$ & $\begin{array}{c}0.387 * * * \\
(0.087)\end{array}$ & $\begin{array}{c}0.387 * * * \\
(0.068)\end{array}$ & $\begin{array}{c}0.279 * * * \\
(0.043)\end{array}$ \\
\hline NI & $\begin{array}{c}-0.209^{* * *} \\
(0.078)\end{array}$ & $\begin{array}{c}-0.209^{* * *} \\
(0.071)\end{array}$ & $\begin{array}{c}-0.209^{* * *} \\
(0.055)\end{array}$ & $\begin{array}{c}-0.211 * * * \\
(0.054)\end{array}$ \\
\hline NP & $\begin{array}{c}-0.193 * * \\
(0.079)\end{array}$ & $\begin{array}{c}-0.193 * * * \\
(0.072)\end{array}$ & $\begin{array}{c}-0.193^{* * *} \\
(0.050)\end{array}$ & $\begin{array}{c}-0.194 * * * \\
(0.048)\end{array}$ \\
\hline NH & $\begin{array}{l}-0.154^{*} \\
(0.082)\end{array}$ & $\begin{array}{l}-0.154 * \\
(0.083)\end{array}$ & $\begin{array}{c}-0.154 * * \\
(0.068)\end{array}$ & $\begin{array}{c}-0.148 * * \\
(0.062)\end{array}$ \\
\hline Ice Breaker & $\begin{array}{r}-0.107^{*} \\
(0.062) \\
\end{array}$ & $\begin{array}{l}-0.107^{*} \\
(0.056) \\
\end{array}$ & $\begin{array}{c}-0.107^{* *} \\
(0.044) \\
\end{array}$ & $\begin{array}{c}-0.089^{* *} \\
(0.036) \\
\end{array}$ \\
\hline $\begin{array}{l}\text { Log-likelihood } \\
\text { AIC } \\
\text { BIC }\end{array}$ & $\begin{array}{c}-109.26 \\
236.52 \\
267.73\end{array}$ & $\begin{array}{c}-109.26 \\
236.52 \\
267.73\end{array}$ & $\begin{array}{c}-109.26 \\
236.52 \\
267.73\end{array}$ & $\begin{array}{c}-109.26 \\
236.52 \\
267.73\end{array}$ \\
\hline
\end{tabular}

Notes: All regressions are based on 237 observations. Marginal effects are reported. Robust/clustered standard errors are reported in parentheses. Three, two, and one stars indicate significance at the $1 \%, 5 \%$, and $10 \%$ levels, respectively. 
Table A3 summarizes the reasons given by high ability types for choosing Option 2 in the post-experimental questionnaire. Reasons are ranked by frequency across all high ability types who choose Option 2 . This is not the order in which participants saw the reasons listed. We only report options chosen by at least $10 \%$ of the subjects. The left column gives data from all five treatments, the middle shows data from the three treatments where teaching is either impossible or unlikely to be beneficial (NI, NP, and NH), and the right reports data from the two treatments (BL and $\mathbf{P R}$ ) where teaching is likely to be beneficial since hints are available and partners are fixed in Stages 2 and 3.

\section{Table A3: Reasons Given by High-Ability Types for Choosing Option 2 in the Post-Experimental Questionnaire}

\begin{tabular}{lccc}
\hline \multicolumn{1}{c}{ Category } & & Frequency & BL and \\
& All Data & NI, NP, and NH & $\begin{array}{c}\text { PR } \\
\text { \# Observations }\end{array}$ \\
Wanted to teach partner & 63 & 17 & 46 \\
Thought communication would motivate partner & $63 \%$ & $35 \%$ & $74 \%$ \\
Prefer to work with others & $28 \%$ & $18 \%$ & $33 \%$ \\
Didn't want to let partner down by not communicating & $28 \%$ & $47 \%$ & $22 \%$ \\
& $25 \%$ & $24 \%$ & $26 \%$ \\
Didn't want to let partner down by not sharing revenue & $22 \%$ & $65 \%$ & $7 \%$ \\
Thought communication would motivate me & $14 \%$ & $18 \%$ & $13 \%$ \\
Thought partner was good at puzzles & $11 \%$ & $18 \%$ & $9 \%$ \\
Thought sharing would motivate partner & $11 \%$ & $18 \%$ & $9 \%$ \\
\hline
\end{tabular}

Notes: Data from post-experimental survey for high ability types who choose Option 2. 


\section{ONLINE APPENDIX 5: ANALYSIS OF THE MESSAGE CONTENT IN THE TREATMENTS}

To measure whether help is being given, we coded all the messages sent between partners who were assigned Option 2 in BL, PR, NP, and NH. Each message was coded independently by two research assistants. The structure of the experiment was explained to the coders, but they were given no information about any hypotheses we had as researchers. They were instructed that they could check as many or few categories as desired. For example, suppose a high ability type writes, "According to the hints, a 7 means you can fill in the whole row." This message provides help and refers explicitly to the hints, so it can be labeled as two different categories (specifically in this case, both Category 1 and Category 3 would be checked). A brief description of the coding categories is given below. Cohen's kappas are high for the categories of greatest interest - those relating to teaching - exceeding .60 in all cases. ${ }^{31}$

\section{Coding Categories}

1. Propose or give help (e.g. suggestions on how to work the puzzles)

2. Ask for help

3. Explicitly referring to the hints (asking to hear about them for low ability types or talking about their content for high ability types)

4. Emotionally supportive comments related to the puzzles (e.g. celebrating getting a puzzle right, commiserating getting a puzzle wrong, encouraging each other, etc.)

5. Social conversation that is unrelated to puzzles

${ }^{31}$ Cohen's kappas are $.891, .678, .722, .476$, and .306 for Categories $1-5$, respectively. Based on feedback from the coders, Categories 4 and 5 were difficult to differentiate because it was often not clear whether or not a comment was related to the puzzles. 
Table A4 summarizes the message content based on the coding exercise, broken down by treatment. The dataset includes all observations where the pair is assigned to Option 2 and chat is possible. Due to the tie-breaking procedure, this includes some individuals who actually choose Option 1 . The unit of measurement is the entire conversation during the feedback following a puzzle. For giving and receiving help, we report the frequency for only one type since we are interested in high ability types giving help to low ability types.

Table A4: Frequency of Chat (per Period)

\begin{tabular}{lcccc}
\hline & BL & PR & NP & NH \\
\hline Either Type, Messages Sent & 6.42 & 8.04 & 5.26 & 5.11 \\
\hline High Ability Type, Messages Sent & 3.76 & 4.31 & 2.78 & 2.69 \\
\hline Low Ability Type, Messages Sent & 2.66 & 3.73 & 2.48 & 2.43 \\
\hline Give Help, Messages Sent by High Ability & 1.73 & 1.49 & 1.09 & 0.53 \\
\hline Ask for Help, Messages Sent by Low Ability & 0.35 & 0.35 & 0.29 & 0.03 \\
\hline Refer to Hints, Messages Sent by Either Type & 1.34 & 1.94 & 1.03 & 0.26 \\
\hline Emotional, Messages Sent by Either Type & 2.06 & 3.03 & 2.04 & 2.50 \\
\hline Social, Messages Sent by Either Type & 2.33 & 3.13 & 2.01 & 2.16 \\
\hline
\end{tabular}


Simple non-parametric tests are inappropriate for establishing whether the frequency of messages and message types differ across treatments because there are obvious selection effects. Table A4 addresses this concern by reporting OLS regressions that use a Heckman correction for selection. We use three separate instruments to control for selection: the difference between the Heckman draws for the low ability type, the difference between the Heckman draws for the high ability type, and the tie breaker for cases where the two partners choose different options (coded as 0 if the tie breaker selects Option 1 and 1 if it selects Option 2). All three of these variables are randomly selected by the experimenter and therefore are exogenous. All three are potentially correlated with the option a subject is assigned. ${ }^{32}$ An observation is the number of messages sent per period by an individual subject in Stage 2. None of the regressions use both partners' data, so there is no need to correct for the correlation between partners' frequencies of interaction. Data from the NI treatment are dropped since there is no interaction. All of the regressions include two controls for ability, specifically the number of puzzles solved in Stage 1 by the low ability type and the high ability type in the pair. The omitted category is the two treatments where teaching is unlikely to have financial benefits (NP and NH). Model 1 considers data from low ability types while Models 2 and 3 use data from high ability types. The dependent variable for Models 1 and 2 is the total number of messages sent per minute, while Model 3 only looks at the provision of help.

Table A5: Number of Messages Sent per Period

\begin{tabular}{cccc}
\hline & Model 1 & Model 2 & Model 3 \\
\hline Ability Type & Low & High & High \\
Type of Message & Any & Any & Help \\
\hline BL + PR & $0.734^{* * *}$ & $1.292^{* * *}$ & $0.742^{* * *}$ \\
\hline Ice Breaker & $(0.288)$ & $(0.339)$ & $(0.221)$ \\
\hline Log-likelihood & $1.123^{* * *}$ & $0.969^{* * *}$ & -0.045 \\
AIC & $(0.301)$ & $(0.350)$ & $(0.224)$ \\
BIC & -294.76 & -315.37 & -266.38 \\
\hline & 611.52 & 652.74 & 558.75 \\
\end{tabular}

Notes: These regressions are based on 187 observations, including 107 participants assigned to Option 2, and use a Heckman correction. Robust standard errors are reported in parentheses. Three (***), two (**), and one $(*)$ stars indicate significance at the $1 \%, 5 \%$, and $10 \%$ level, respectively.

\footnotetext{
${ }^{32}$ Looking at first stage results, the difference between the Heckman draws for the low ability type and the tie breaker are significant at the $1 \%$ level in all four models. The difference between Heckman draws for the high ability type is never significant. This is consistent with results reported in Table 3.
} 


\section{ONLINE APPENDIX 6: ANALYSIS OF PERFORMANCE}

Table A6: Number of Puzzles Solved by High Ability Types in Stages 2 and 3

\begin{tabular}{cccc}
\hline & Option 1 & Option 2 & Estimated Difference $(p$-value $)$ \\
\hline BL & 6.81 & 7.03 & $0.611(0.229)$ \\
PR & 7.00 & 7.16 & $0.991(0.088)$ \\
NI & 7.28 & 7.00 & $-0.212(0.750)$ \\
NP & 7.26 & 6.68 & $-0.802(0.114)$ \\
NH & 6.85 & 6.52 & $-0.022(0.967)$ \\
\hline
\end{tabular}

